\title{
Improving the measurement of environmental sensitivity in children and adolescents: The Highly Sensitive Child scale 21-item version
}

\author{
Sofie Weyn ${ }^{1}$ \\ Karla Van Leeuwen ${ }^{1}$ \\ Michael Pluess ${ }^{2}$ \\ Francesca Lionetti ${ }^{2,3}$ \\ Luc Goossens $^{1}$ \\ Guy Bosmans ${ }^{1}$ \\ Wim Van Den Noortgate ${ }^{1}$ \\ Dries Debeer ${ }^{1}$ \\ Anne Sophie Bröhl ${ }^{1}$ \\ Patricia Bijttebier ${ }^{1}$
}

\footnotetext{
${ }^{1}$ KU Leuven, Belgium

${ }^{2}$ Queen Mary University of London, UK

${ }^{3}$ Department of Neuroscience, Imaging and Clinical Science, University 'G. D’Annunzio’ of Chieti-Pescara, Chieti, Italy
}

\section{Corresponding author:}

Sofie Weyn

School Psychology and Development in Context

Tiensestraat 102 box 3717, Belgium

sofie.weyn@kuleuven.be

$+3216376734$ 


\section{Acknowledgements and funding:}

We would like to express our gratitude to all the participating early adolescents from the primary and secondary schools in Belgium and the Netherlands as well as their parents and teachers. The Methylation and Internalizing Problem Behaviors in Adolescence: Examining Associations Across Multiple Levels of Analysis (MIND) project received financial support for the research, authorship, and/or publication of this article: This project was supported by a C1grant (C14/16/040) from the KU Leuven Research Fund.

Conflict of Interest: The authors declare that they have no conflict of interest. 


\begin{abstract}
Children differ in their sensitivity to positive and negative environmental influences, which can be measured with the Highly Sensitive Child (HSC) scale. The present study introduces the HSC21, an adaptation of the original 12 item scale with new items and factor structure that are meant to be more informative than the original ones. The psychometric properties of the HSC-21 were investigated in 1,088 children across Belgium and the Netherlands, including child and mother reports. Results showed evidence for (a) bifactor model with a general sensitivity factor and two specific factors (i.e., Ease of Excitation-Low Sensory Threshold and Aesthetic Sensitivity), (b) (partial) measurement invariance across gender, developmental stage, country, and informants, (c) moderate child-mother agreement, (d) good reliability, (e) normally distributed item scores, and (f) meaningful associations with personality and temperament across both samples. No evidence was found for HSC-21 as a moderator in the relationship between parenting and problem behaviors.
\end{abstract}

Keywords: Environmental Sensitivity; Sensory Processing Sensitivity; Children; Early adolescents, Psychometric properties; Multi-informants 
Children and adolescents differ in their environmental sensitivity (Greven et al., 2019; Pluess, 2015), which is the ability to perceive and process environmental stimuli more deeply and broadly. Highly sensitive children and adolescents seem to be more affected by negative environments such as negative controlling parenting (Slagt et al., 2018), but can also benefit more from positive environments such as supportive parenting (Pluess, 2015; Slagt et al., 2018). These findings are in line with the differential susceptibility framework (Belsky \& Pluess, 2009) that states that more sensitive individuals are more sensitive to both negative and positive environments, in comparison with less sensitive individuals who are less affected by environmental stimuli.

Several studies that investigated individual differences in sensitivity to environmental influences focused on genetic polymorphisms (Caspi et al., 2003), stress reactivity (El-Sheikh et al., 2007), or infant temperament (Slagt et al., 2018). However, a more proximate marker of environmental sensitivity seems to be sensory processing sensitivity (SPS; Aron \& Aron, 1997; Slagt et al., 2018). Individuals high in SPS would be more (a) emotionally reactive and empathic, (b) easily overstimulated, (c) behaviorally inhibited in new situations, and (d) aware of subtleties in their environment. Moreover, they would process environmental information more deeply (Aron \& Aron, 1997; Greven et al., 2019). In adults, SPS can be measured with the Highly Sensitive Person (HSP; Aron \& Aron, 1997) scale. Scores on the HSP scale have been shown to be reliable and valid across different samples (e.g., Lionetti et al., 2018). Factor analysis showed evidence for a bifactor structure (Lionetti et al., 2018) with a general sensitivity dimension and three specific dimensions: Ease of Excitation (EOE; e.g., being easily overwhelmed in crowded situations or when having a lot to do in a small amount of time), Low Sensory Threshold (LST; e.g., the negative feeling caused by sensory stimuli such as loud noises, bright lights, or being 
touched), and Aesthetic Sensitivity (AES; e.g., being aware of subtleties in the environment, such as details, nice smells and flavors).

\section{The Highly Sensitive Child Scale}

Pluess et al. (2018) developed a variant of the HSP scale, which was referred to as the Highly Sensitive Child (HSC) scale, to measure environmental sensitivity in children from 8 years onward. This scale consists of 12 items (Supplementary Material 1; items in bold) that reflect the same three dimensions as the HSP scale, namely EOE (5 items), LST (3 items), and AES (4 items; Pluess et al., 2018). The psychometric properties of the HSC scale were examined in different samples in the UK (Pluess et al., 2018) and Belgium (Weyn et al., 2019). Across these samples, evidence was found for a bifactor model (Figure 1) with a general sensitivity factor (HSC) and three specific factors (i.e. EOE, LST, and AES). Weyn et al. (2019) showed that the general and the specific factors explained an important amount of variance in the HSC scores, with most overlap in the variance explained by the general, LST, and EOE factors. They found good internal consistency values of the scores on the total scale and the EOE subscale, but weaker internal consistency values of the scores on the AES and LST subscales in multiple samples. Intercorrelations among the different subscales of environmental sensitivity showed high associations between the EOE and LST scale but lower associations with AES. The different specific dimensions seemed to be moderately associated with different domains of temperament and personality. EOE and LST were positively related to Neuroticism and Negative Affect and negatively with Extraversion, whereas AES was positively related to Openness and Extraversion. Based on these results, AES seems to capture another part of sensitivity (which may reflect a sensitivity to positive stimuli) than the LST and EOE subscales (which may reflect a sensitivity to negative stimuli; Pluess et al., 2018; Weyn et al., 2019). 
Evidence was found for partial metric and partial scalar measurement invariance across gender, developmental stage, and country. These results suggested that the groups do not attribute the same meaning to all the items (i.e., partial metric invariance) and do not always use the same reference point (i.e., partial scalar invariance; Weyn et al., 2019). Therefore, children who are similar in environmental sensitivity may score differently on the HSC scale (Schmitt et al., 2011).

Despite some limitations regarding reliability and measurement invariance, studies showed that the HSC scale does capture individual differences in environmental sensitivity. A longitudinal study found that environmental sensitivity interacted with changes in both negative and positive parenting in predicting externalizing problems (Slagt et al., 2018). Intervention studies found that children scoring high on the HSC scale benefitted more from an anti-bullying intervention (Nocentini et al., 2018) and from a school-based depression prevention program (Pluess \& Boniwell, 2015), than children scoring lower on the HSC scale. These studies indicated that children scoring high on environmental sensitivity were more sensitive to parenting and intervention programs than children scoring low or average on environmental sensitivity, which might have important implications for further research and clinical interventions.

\section{Toward an Improved Version of the Highly Sensitive Child Scale}

Because previous studies in samples with children and adolescents indicated that the internal consistency values of scores on the AES and LST subscales were weak in the examined samples (Pluess et al., 2018; Weyn et al., 2019) and that the HSC scale was only partially measurement invariant across gender, developmental stage and country, Weyn et al. (2019) looked more in detail at the distribution of the scores and the content of the items. Results showed that the scores on the (a) EOE scale were approximately normally distributed, (b) those on the AES scale were negatively skewed (i.e., ceiling effects), and (c) those on the LST scale 
were more positively skewed. By examining the item content of the scales for which the scores were skewed, the authors found that the skewness was possibly due to the wordings of some items that did not show much variation in responses (e.g., "I love nice tastes' or 'I love nice smells"'). As a consequence, these items had overall high scores and did not differentiate well between low and high sensitive children. One item of LST ("I don't like watching TV programs with a lot of violence in them") showed a weak association with the LST total scale, probably because the negation it the wording of the item, which might be difficult for children to answer on a 7-point Likert scale. Moreover, two out of three items of the LST subscale refer to being sensitive to loud noises only, whereas based on literature (Aron \& Aron, 1997; Greven et al., 2019), we would expect that children scoring high on environmental sensitivity would be more sensitive to a broader range of sensory stimuli (e.g., bright lights, being touched, strong smells, and itchy fabrics).

\section{The Present Study}

Based on these limitations (i.e., the lower internal consistency of the item scores on the HSC scale, the skewed distribution of the LST and AES subscale, the limited discriminative value of the AES subscale, the evidence for only partial metric and scalar invariance, and the limited scope of items of the LST subscale), we aimed to improve the HSC scale by developing new items that capture the construct more broadly and that allow more variation in responses, while starting from the existing structure (i.e., EOE, LST, AES). In what follows, we describe how the new items were developed and which criteria were used to select the final set of items. Next, we examined the following psychometric properties of the adapted scale: (a) the factor structure, (b) measurement invariance across developmental stage, gender, country, and informants, (c) agreement between child and mother reports, (d) the internal consistency, and (e) 
the distribution of the item scores of the adapted HSC scale in two different samples (i.e., Belgian and Dutch sample) with different informants (i.e., child and mother reports). Finally, as a first validity check we investigated (a) the associations between different dimensions of environmental sensitivity and well-studied domains of personality and temperament (i.e., convergent and discriminant validity) and (b) whether scores on the HSC scale are a moderator in the relationship between negative and positive environmental factors (i.e., negative and positive parenting) and outcomes (i.e., internalizing and externalizing problem behaviors; criterion validity). Based on the literature we expect that (a) items capturing EOE and LST are positively associated with Neuroticism and Negative Affect and negatively with Extraversion, (b) items capturing AES are positively associated with Openness, Extraversion, and Orienting Sensitivity (e.g., Pluess et al., 2018; Weyn et al., 2019), and (c) children scoring high on environmental sensitivity are more sensitive to both negative and positive environments (e.g., Greven et al., 2019).

\section{Method}

\section{Participants and Procedure}

Data from two cross-sectional samples were used. Sample 1 includes Wave 1 data of the [omitted for blinded review], a longitudinal study in which children from Grade 5 across different participating schools $(N=96)$ of the Dutch speaking part of Belgium and their parents were invited to participate. In total, active consent for participation was received from 629 early adolescents from Grade $5\left(M_{\mathrm{age}}=10.77, S D_{\mathrm{age}}=0.48\right.$, boys $=45.1 \%, 91.1 \%$ Caucasian $[0.5 \%$ African, 8.4\% missing]) and their parents. Early adolescents completed the extended version of the HSC scale (38-items, see Supplementary Material 1). In addition, mothers $(n=417 ; 99.1 \%$ biological mother [0.7\% stepmother, $0.2 \%$ adoptive mother]; $10.4 \%$ single mother; $83.7 \%$ highly 
educated; 30.2\% fulltime employed, $62.8 \%$ part-time employed, $8.1 \%$ unemployed) reported on their parenting and on their child's personality, temperament, internalizing and externalizing problem behaviors. Sample 2 includes data of Wave 1 of the [omitted for blinded review], conducted in the Southern part of the Netherlands. In total, 16 schools agreed to participate in the study. From Grade 1 to 6 mothers were invited to report on their parenting and on their child's sensitivity, personality, temperament, internalizing and externalizing problem behaviors. From Grade 5 children were invited to report on their own sensitivity. This resulted in active consent for participation of 151 early adolescents from Grade 5 to $8\left(M_{\text {age }}=12.57, S D_{\text {age }}=1.37\right.$; boys $=$ 41.2\%; nationality was not reported by children) and 542 mothers of children from Grade 1 to 6 (characteristics child: $M_{\mathrm{age}}=9.91, S D_{\mathrm{age}}=2.12$, boys $=52.7 \%, 97 \%$ Caucasian; characteristics family: $99.8 \%$ biological mother [ $0.2 \%$ foster mother], $10.4 \%$ single mother, $70.2 \%$ highly educated [missing: $8.2 \%$ ], 3.2\% fulltime employed, $62.8 \%$ part-time employed, $8.1 \%$ unemployed) participated. Because we only included self-reports from Grade 5 and because mothers could give active consent for the participation of their child without participating themselves, we only received both child and mother reports for 101 early adolescents $\left(M_{\mathrm{age}}=\right.$ 12.02, $S D_{\text {age }}=1.14$; boys $=44.5 \% ; 99 \%$ Caucasian; $100 \%$ biological mother; $10.9 \%$ single mother; $60.4 \%$ highly educated [14.9\% missing]; $22.7 \%$ fulltime employed, $67.7 \%$ part-time employed, 9.6\% unemployed). Both early adolescents and their mothers completed the extended version of the HSC scale. In addition, mothers filled out questionnaires regarding parenting and their child's internalizing and externalizing problem behaviors. All questionnaires were completed on a computer that gave an alert (with the exception of demographic questions) when not all items were completed. Therefore, there were no missing data in Sample 2. In both projects, there were no exclusion criteria for participation. Both projects were approved by the university's ethics committee. 


\section{Instruments}

\section{Environmental Sensitivity}

Environmental sensitivity was measured using an extended version of the Highly Sensitive Child scale (HSC) scale (38 items; Supplementary Material 1), which was developed by adding 26 new items to the original HSC scale (Pluess et al., 2018). The new items were developed by (a) identifying important aspects (e.g., emotional reactivity, behavioral inhibition, depth of processing, and being aware of subtleties in the environment) and domains (i.e., ease of excitation, low sensory threshold, and aesthetic sensitivity) of environmental sensitivity that are based on literature (e.g., Aron \& Aron, 1997; Greven et al., 2019; Pluess et al., 2018), (b) with the help of experts in the field, and (c) while taking into account the appropriateness and comprehensibility of the items for children from 8 year onwards. The new items were meant to capture the subdomains of environmental sensitivity more broadly (e.g., not only sensitivity to loud noises, but also sensitivity to other sensory stimuli such as lights, scents, and tactile stimulations) and to allow more variation in responses, while fitting the existing subdomains of environmental sensitivity (i.e., EOE, LST, and AES). The new items were developed in Dutch but were translated into English (for research purposes, see Supplementary Material 1) by a native English speaker and back-translated by an independent person into Dutch in order to check whether the meaning of the items was preserved by translating them. The Dutch version can be obtained from the first author. The extended scale comprises items capturing the EOE scale $(n=$ 6, with 1 extra, i.e., "In crowded places I quickly get overwhelmed.”), the LST scale ( $n=16$, with 14 extra, e.g., "I find coarse or itchy fabrics unpleasant."), and the AES scale ( $n=15$, with 11 extra, e.g., "I am good at distinguishing different tastes."). For the EOE scale, only one extra item was developed because the original items captured the construct of EOE already well (i.e., "being easily overstimulated by external and internal incentives"; Greven et al., 2019) and differentiated 
well between individuals (i.e., no ceiling or floor effects). Early adolescents answered items on a 7-point Likert scale ranging from 1 (not at all true) to 7 (extremely true).

\section{Personality}

Personality was measured with the Hierarchical Personality Inventory for Children (HiPIC; Mervielde et al., 2009). The HiPIC is based on the Five Factor model of personality (i.e., Neuroticism, Extraversion, Openness, Agreeableness, and Conscientiousness; McCrae \& Costa, 1987) and consists of 144 items. The instrument has five subscales, that are, Emotional stability (or the opposite of Neuroticism; e.g., "My child worries quickly about things"), Extraversion (“" My child talks easily to people“), Imagination (a label for Openness; e.g., "My child has a rich imagination"), Benevolence (or Agreeableness; e.g., "My child grants also something to others"), and Conscientiousness (e.g., "My child finishes tasks to the very end"). All items were answered by mothers on a 5-point Likert-type scale ranging from 1 (very untypical) to 5 (very typical). The internal consistency values of the item scores on personality in both samples were good. The descriptive statistics and internal consistency values of the item scores on the personality subscales are reported in Table 1.

\section{Temperament}

Temperament was measured with the short version of the Adult Temperament Questionnaire (ATQ) ${ }^{1}$, which is developed based on the temperament model of Rothbart (Evans \& Rothbart, 2007) and consists of 77 items. The ATQ consists of four subscales measuring four

${ }^{1}$ The adult — instead of child — version of the Rotbarth's temperament questionnaires was chosen because it measures Orienting Sensitivity. Orienting Sensitivity is—-based on item content—believed to be associated with environmental sensitivity, but is not captured by the child version of the scale: Early Adolescent Temperament Questionnaire-Revised (EATQ-R; Capaldi \& Rothbart, 1992). 
domains of temperament: Negative affect (e.g., "My child becomes easily frightened.”), Effortful control (e.g., "My child is often late for appointments."), Extraversion (e.g., "Sometimes minor events cause my child to feel intensely happy."), and Orienting sensitivity (e.g., reversed-coded item: "Barely noticeable visible details rarely catch my child's attention."). All items were answered by mothers on a 5-point Likert-type scale ranging from 1 (not at all) to 7 (completely). The internal consistency values of the item scores on the temperament subscales in both samples were good. The descriptive statistics and internal consistency values of the item scores on the temperament subscales are reported in Table 1.

\section{Parenting}

Positive parenting was measured using the Parental Support subscale (e.g., "If my child wants to tell something, I make time to listen to him or her.") of the short version of the Parental Behavior Scale (PBS-S; Van Leeuwen et al., 2018). Negative parenting was measured using the Psychological Control scale (e.g., "I do not talk to my son/daughter when he/she has disappointed me, until he/she pleases me again.”) of the Parental Regulation Scale (PRS-YSR; Soenens et al., 2006). All items were rated by mothers on a 5-point Likert scale ranging from 1 ([almost $]$ never) to 5 ([almost $]$ always). The internal consistency values of the item scores on the parenting subscales in both samples were good. The descriptive statistics and internal consistency values of the item scores on parenting are reported in Table 1.

\section{Externalizing Problem Behavior}

In Sample 1, externalizing problem behavior was measured by means of the raw scores on the broad-band Externalizing Problem scale (e.g., "My child breaks rules at home, school, or elsewhere.") of the Child Behavior Checklist (CBCL; Achenbach, 1991a). Mothers reported on a 3-point Likert scale ranging from 0 (Not at all) to 2 (Obvious or often). In Sample 2, externalizing problem behavior was measured with the mean of the subscales Conduct Problems 
(e.g., "My child often has temper tantrums or a hot temper.") and Hyperactivity/Attentional problems (e.g., "My child is easily distracted, has troubles with concentrating.") of the Strengths and Difficulties Questionnaire (SDQ; Goodman, 1997), which were answered by mothers on a 3point Likert scale ranging from 1 (Not true) to 3 (Definitely true). The internal consistency values of the item scores on externalizing problem behavior in both samples were good. The descriptive statistics and internal consistency values of the item scores on externalizing problem behavior are reported in Table 1.

\section{Internalizing Problem Behavior}

In both samples internalizing problem behavior was measured using the raw scores on the broad-band Internalizing Problem scale of the CBCL (Achenbach, 1991a), which was answered by mothers on a 3-point Likert scale ranging from 0 (Not at all) to 2 (Obvious or often). In both samples, the internal consistency values of the item scores on the Internalizing Problem Behavior scale were good. The descriptive statistics and internal consistency values of the item scores on internalizing problem behaviors are reported in Table 1.

\section{Data Analyses}

\section{Factor Structure and Item Selection}

Sample 1 was randomly split into a calibration ( $n=315,6.40 \%$ missing HSC data) and validation ( $n=314,4.94 \%$ missing HSC data) sample. In both samples Little (1988) missing completely at random (MCAR) test was not significant: $\chi^{2}(1439.59), d f=1401, p=.23$ (Sample 1) and $\chi^{2}(1311.68), d f=1274, p=.23$ (Sample 2). The number of factors and the best functioning items were selected based on theory and results from the Hull method (Lorenzo-Seva et al., 2011), exploratory structural equation modelling (ESEM; Asparouhov \& Muthén, 2009; Marsh et al., 2014), and multidimensional item response theory (MIRT; Reckase, 2009) in the 
calibration sample. Before running these analyses, four original items were omitted. Three items (original Item 3: "I love nice smells.", 5: "Some music can make me really happy.", and 10: "I love nice tastes.") were omitted from the analyses because previous research showed that these items were negatively skewed and did not show much variation in responses across multiple samples (Weyn et al., 2019). Also original Item 7 (“I don't like watching TV programs with a lot of violence in them.") was omitted because we noticed during data collection that a lot of children had difficulties to answer this item on a 7-point Likert scale, probably due to the negation in $\mathrm{it}^{2}$.

The Hull method, which aims to find an optimal balance between the model fit and the amount of parameters, was used to determine the number of common factors (hullEFA package in $\mathrm{R}$ version 4.0.1, with maximum likelihood [ML] as extraction method and common part accounted for $[\mathrm{CAF}]$ index). To control for missing data, the analyses were repeated on five multiple imputed data sets.

ESEM integrates the advantages of an exploratory factor analysis (EFA; e.g., all factors can freely load on all indicators) and a confirmatory factor analysis (CFA, which is part of SEM; e.g., model fit indices and a priori hypotheses on factor structure). ESEM allows to specify the expected factor structure (based on theoretical considerations; i.e., EOE, LST, AES), while freely estimating all cross-loadings (i.e., non-zero loadings on other than a prioir defined factors; Booth \& Hughes, 2014; Gomes et al., 2017; Marsh et al., 2014). ESEM models were run using robust

\footnotetext{
${ }^{2}$ As a sensitivity analysis, we re-ran the analyses with the inclusion of the four original problematic items
} that were omitted before running the analyses. Both factor loadings (ESEM) and discrimination parameters (MIRT) indicated that these items were not informative. The conclusions and decisions did not change by including the problematic items. Therefore, we only report the results without including the problematic items in the analyses. 
maximum likelihood (MLR) and target rotation in Mplus (Version 8.2). Full information maximum likelihood (FIML; Arbuckle, 1996) was used to deal with missing data. The results from the ESEM and Hull approach results were used to determine the number of factors.

MIRT is a multidimensional extension of the unidimensional item response theory (IRT). IRT is a theoretical framework that states that an individual's response to an item depends on specific item (i.e., item discrimination and item threshold) and person (i.e., a person's ability or position on the latent trait, such as environmental sensitivity) characteristics. In graded response IRT models, which are used for polytomous items (e.g., Likert scale items), the item discrimination (called slope $[a]$ in MIRT) indicates how well an item differentiates between individuals along a continuum of the underlying trait and is analogous to factor loadings in a classical test theory framework, such as ESEM. The higher the discrimination parameter, the more informative an item is, or the more an item differentiates among people at different degrees of the underlying trait. The item threshold parameters, or category boundary intercept parameter in MIRT $(d)$ refer to the latent trait value(s) for which there is a $50 \%$ probability of responding higher than the category corresponding with the threshold. The latent traits are assumed to follow a multivariate standard normal distribution, for reasons of model identification. One advantage of IRT is that the item parameters are independent of the sample (e.g., Immekus et al., 2019; Osteen, 2010; Sharkness \& DeAngelo, 2011). A MIRT graded response model with two dimensions was fitted (in MIRT package in R Version 4.1) parallel to ESEM to examine how well the HSC items $(n=34)$ differentiate among individuals and at which positions on the trait continuum (i.e., the examined dimensions of environmental sensitivity) the items are most informative. FIML was used to deal with missing data.

The information from previous analyses and theory were combined to select a final pool of items. Items were omitted when ESEM factor loadings were <.40 (e.g., Boateng et al., 2018) 
and when the MIRT slope parameters were $<.65$. MIRT discrimination parameters between 1.35 and 1.70 were considered as high, above 1.70 was considered as very high (Baker, 2001; Sharkness \& DeAngelo, 2011). The final factor structure with the retained items was again tested in ESEM to evaluate the model fit. Based on the modification indices, correlated errors between highly correlated items that could be theoretically justified (e.g., tapping into similar content such as the same sensory modality), were added to the model (Brown, 2015).

\section{Validation of the Factor Structure of the Adapted HSC Scale}

After the number of factors and well-functioning items were selected in the calibration sample, the factor structure with the final item pool was evaluated in Sample 1 (validation part, $n$ $=314$ ) and Sample 2 (child and mother reports) using CFA, in which the cross-loadings of items are constrained to be zero (Boateng et al., 2018). Because previous studies using the original HSC items found evidence for a bifactor model (Pluess et al., 2018; Weyn et al., 2019), the fit of a correlated-trait model (first-order factor structure) was compared to the fit of a bifactor model (second-order factor structure) with the same first-order factors as the correlated trait model. Bifactor models allow to investigate whether potential overlap in factors is due to a general factor. CFAs were conducted in R (Version 4.0.1, lavaan package), using maximum likelihood robust (MLR) to address non-normality (Satorra \& Bentler, 1994) and FIML to deal with missing data. Model fit was considered acceptable when (a) the comparative fit index (CFI) was at least .90 , (b) the root mean square error of approximation (RMSEA) was not larger than .06, and (c) the standardized root mean squared residual (SRMR) was maximally .08 (Kline, 2005). A model was considered to fit the data as substantially different from the other model when $\triangle \mathrm{CFI}$ was .010 or more, $\triangle \mathrm{RMSEA}$ was at least .015 , and $\triangle \mathrm{SRMR}$ was .010 or more (Chen, 2007). The samplesize-adjusted Akaike information criterion (AICc) and Bayesian information criterion (aBIC) were used as comparative fit indices; a smaller AICc and aBIC value indicating a better fit. 
Burnham and Anderson (2004) specified some rules of thumb when comparing the AICc values of two models. When $\triangle \mathrm{AICc}$ is not larger than 2 , there is still substantial support for the model having a higher AICc value, when $\triangle \mathrm{AICc}$ is between 4 and 7 there is considerably less support for the model having a higher AICc value, and when $\triangle \mathrm{AICc}$ is larger than 10 , there is no support for the model having a higher AICc value. For $\triangle \mathrm{aBIC}$, we applied the same rules of thumb as for $\triangle \mathrm{AICc}$ (Raftery, 1995).

\section{Measurement Invariance of the Adapted HSC scale}

From these analyses onwards, the calibration and validation subsample of Sample 1 were merged again $(N=639)$. Next, measurement invariance of the HSC scale was evaluated. Because previous research (Weyn et al., 2019) indicated that the HSC scale was only partially measurement invariant across gender and developmental stage, the measurement invariance of the adapted HSC scale was first evaluated across gender (in Sample 1 and 2, separately) and developmental stage (in Sample 2 across participants in primary and secondary school) ${ }^{3}$. Next, we tested whether the adapted HSC scale was measurement invariant across Belgium and the Netherlands and across child and mother reports. Measurement invariance was tested at three levels. First, we checked whether the factor structure of the adapted HSC scale was invariant across groups (i.e., gender, developmental stage, country, and informant; i.e., configural measurement invariance) by running a multigroup CFA in R (Version 4.0.1, package lavaan). Next, we checked whether the factor loadings were similar across these groups (i.e., metric measurement invariance). Finally, we tested whether intercepts were invariant across these groups (i.e., scalar measurement invariance). Configural invariance was established when (a) CFI

\footnotetext{
${ }^{3}$ In Sample 2 only mother reported data were used due to the small sample size of the child reported data.
} 
was at least .90, (b) RMSEA was not higher than .06, and (c) SRMR was not higher than .08. Metric and scalar invariance were established when $\Delta$ CFI between the non-constrained and constrained model was smaller than .010, $\triangle$ RMSEA between the non-constrained and constrained model was smaller than .015 , and $\triangle$ SRMR between both models was smaller than .030 (metric invariance) or .010 (scalar invariance; Chen, 2007). Based on simulation studies, when comparing nested models one should first rely on $\triangle \mathrm{CFI}, \triangle \mathrm{RMSEA}$ and $\triangle \mathrm{SRMR}$ could be considered as well, but they should be given less weight (Sellbom \& Tellegen, 2019). Partial metric and/or scalar measurement invariance was established when at least two factor loadings and/or intercepts per latent factor were invariant (Byrne et al., 1989).

\section{Internal Consistency and Dimensionality of the Adapted HSC Scale}

The internal consistency of the item scores on the extended version were examined by calculating Cronbach's alpha ( $\alpha$ ), McDonald's (McDonald, 1999) omega ( $\omega)$, and McDonald's hierarchical omega $\left(\omega_{\mathrm{H} / \mathrm{S}}\right)$ in R (packages BifactorIndicesCalculator and MBESS). McDonald's $\omega$ is a factor model based coefficient of internal consistency that does not rely on tau-equivalence assumptions as Cronbach's $\alpha$ does (e.g., Revelle \& Zinbarg, 2008; Zinbarg et al., 2005). Therefore, McDonald's $\omega$ is more realistic and less sensitive to over- and underestimations of internal consistency than Cronbach's $\alpha$ (Dunn et al., 2014). Cronbach's $\alpha$ of .60 or lower were considered as low, between .60 and .70 as acceptable, and .70 or higher as a good (Leary, 2008). For McDonald's $\omega$, we applied the same rules. For bifactor models, McDonald's omega hierarchical of the general factor $\left(\omega_{\mathrm{H}}\right)$ and specific factors $\left(\omega_{\mathrm{S}}\right)$ are important model-based reliability indices because they separate the proportion of variance in the item scores that is attributed to the general and each specific factor while controlling for each other (i.e., the variance in item scores explained by the general factor while controlling for proportion of 
variance explained by the specific factors, and vice versa; e.g., Rodriguez et al., 2015). Finally, the explained common variance (Sijtsma, 2008), which reflects the strength of the general factor, was computed. Higher values (e.g., >.80) indicate a strong general factor and supports the use of a unidimensional model, even to multidimensional data (Rodriguez et al., 2015).

\section{Descriptive Statistics and Agreement Between Child and Mother Reports of the Adapted HSC}

Scale.

In Sample 1 and 2, the means, medians, standard deviations, skewness, and intercorrelations among the subscales of the adapted HSC scale were examined and compared with the descriptives when using only the 12 original items. When at least partial measurement invariance is established, we will compare the agreement between child and mother reports by examining the correlations between the different dimensions of the adapted HSC scale.

According to Cohen (1988), a correlation coefficient between .10 and .30 is considered as small, a coefficient between .30 and .50 as medium, and a coefficient of .50 or larger as large.

\section{Convergent and Discriminant Validity: The Association of the Adapted HSC Scale With Well-}

\section{Studied Domains of Personality and Temperament}

In order to investigate whether the adapted version of the HSC scale is associated with (i.e., convergent validity), but still different from (i.e., discriminant validity), well-studied domains of personality and temperament, we investigated the associations between the different dimensions of the adapted HSC scale (reported by children in Sample 1 and by mothers in Sample 2) and different domains of personality (i.e., Neuroticism, Extraversion, Openness, Agreeableness, and Conscientiousness) and temperament (i.e., Negative Affect, Effortful Control, Extraversion, and Orienting Sensitivity), which were reported by mothers in both samples. Both bivariate zero-order and partial correlations were estimated in Sample 1 and 2 using SPSS 
(Version 26). In order to deal with missing values in Sample 1 (10\%, Little's MCAR test did not converge), the results across five imputed data sets were pooled.

\section{Criterion Validity: The Adapted HSC Scale as a Moderator of Environmental Stimuli}

In order to validate whether the extended HSC scale indeed captures individual differences in sensitivity to the environment, we tested hierarchical regression models in SPSS (Version 26). In both samples we ran hierarchical regression analysis for each dependent variable (i.e., externalizing and internalizing problem behaviors) separately. As a first step, we included control variables age and gender. In a second step, we included the standardized parenting (i.e., positive and negative parenting) and environmental sensitivity (i.e., HSC total or subscales) variables. As a third step, we included the interaction terms between the standardized parenting and environmental sensitivity variables. Parenting and outcome measures were reported by mothers and environmental sensitivity was reported by early adolescents in Sample 1 and by mothers in Sample 2 (because of a small number of child reports in Sample 2). Variance inflation factor (VIF) was examined to evaluate multicollinearity in the data (a proposed cutoff is VIF > 10, indicating severe multicollinearity; Menard, 1995). In order to deal with the missing values in Sample $1(10 \%$, Little's MCAR test did not converge), the results across five imputed data sets were pooled.

\section{Results}

\section{Factor Selection and Item Reduction}

Although the Hull method indicated that a model with two dimensions provided the best fit (Figure S1), we fitted both a two-factor and a three-factor model using ESEM, because the original HSC scale assumed three underlying traits (Pluess et al., 2018). However, in the threefactor ESEM model, the items that were a priori assigned to the EOE factor did not load on this 
factor. Furthermore, these items had high factor loadings on the LST factor, as did the items that were a priori assigned to LST (Table S1). Therefore, in the two-factor ESEM model, the EOE and LST items were a prior assigned to one factor ${ }^{4}$. In parallel, but treating the response scale as ordered categorically, a MIRT model with two a priori defined dimensions (i.e., EOE-LST and AES) was fit to the data. Based on theoretical considerations and the results of the ESEM and MIRT analysis, items were selected. To be more precise, items with factor loadings $<.40$ (ESEM), slope parameters $<.65$ (MIRT), or with an inappropriate range of category boundary intercept parameters (MIRT) were considered for dropping if there was no theoretical justification (e.g., an aspect of environmental sensitivity that was not yet captured by the other retained items) for maintaining these items in the scale. This process resulted in a selected item pool of 21 well-functioning or informative items. All selected items had a factor loading $\geq .40$ (except HSC1: "I notice when small things have changed in my environment", which had a factor loading of .38 but a slope of 1.21 and is considered as theoretically meaningful for the AES construct). According to the MIRT category boundary intercept parameter results, all items were informative along a wide range of the relevant underlying trait. Three items, however, were slightly more informative towards the extremes of the relevant traits: HSC21: "I get upset when other children touch me." and HSC 35: "I am sensitive to being touched." were slightly more informative for children scoring above average on EOE-LST; HSC15: "I immediately notice when someone has new clothes or a new haircut." was slightly more informative for children scoring below average or average on AES. ESEM and MIRT results per item are reported in

\footnotetext{
${ }^{4}$ Note that this is partially in line with the findings of Pluess et al., (2018) and Weyn et al., (2019) who found that EOE and LST were moderately to highly correlated with each other and associated with similar personality and temperament traits across multiple samples.
} 
Table 2 . Of the initial 34 items only 21 were retained. Nevertheless, the content of the remaining items seems to cover the conceptual definition of environmental sensitivity across the different dimensions, that are, ease of excitation, low sensory threshold, and aesthetic sensitivity (Greven et al., 2019; Pluess et al., 2018), sufficiently.

Finally, within the ESEM framework the fit of the two-factor solution with 21 items (EOE-LST: $n=13$, AES: $n=8$ ) was optimized by allowing correlated error terms between highly correlated items tapping similar item content (e.g., between items HSC19 ("I have a delicate sense of smell.") and HSC7 (“I quickly notice how something smells.", for a complete overview, see Table S2). The final model fitted the data in the calibration sample well (CFI = .946; TLI $=$ $.928 ; \mathrm{RMSEA}=.036 ; \mathrm{SRMR}=.041)$. The standardized factor loadings of the final two-factor model in the calibration sample are presented in Table 3.

\section{Validation of the Factor Structure of the HSC-21 Scale}

The fit of a two-factor correlated traits model (first-order model) was evaluated and compared to the fit of a bifactor model with the same two specific first-order factors (secondorder model) in the validation part of Sample 1 and in Sample 2 (child and mother reports). In Sample 1, CFA results indicated an acceptable model fit for the two-factor solution (validation: $\mathrm{CFI}=.889 ; \mathrm{TLI}=.867, \mathrm{RMSEA}=.050 ; \mathrm{SRMR}=.060 ; \mathrm{AICc}=23851.12 ; \mathrm{aBIC}=23841.641)$ and an acceptable model fit of the bifactor solution $(\mathrm{CFI}=.929 ; \mathrm{TLI}=.906, \mathrm{RMSEA}=.042$; $\mathrm{SRMR}=.048 ; \mathrm{AICc}=23848.07 ; \mathrm{aBIC}=23811.728)$. For the two-factor model, only the CFI and TLI were $<.90$, which might not be informative because the baseline model's RMSEA $(0.140)$ was $<.158$, meaning it is unlikely to have CFI/TLI values $>.90$ (Rigdon, 1996). In Sample 2, CFA showed a non-acceptable model fit for a two-factor $(\mathrm{CFI}=.867$; $\mathrm{TLI}=.842, \mathrm{RMSEA}=$ $.079 ; \mathrm{SRMR}=.086 ; \mathrm{AICc}=11132.24 ; \mathrm{aBIC}=10975.267)$ and bifactor solution $(\mathrm{CFI}=.896$; 
$\mathrm{TLI}=.862 . \mathrm{RMSEA}=.074 ; \mathrm{SRMR}=.064 ; \mathrm{AICc}=11268.7 ; \mathrm{aBIC}=10935.900)$ when using selfreported data, but an acceptable and good model fit for the two-factor $(\mathrm{CFI}=.939 ; \mathrm{TLI}=.928$, $\mathrm{RMSEA}=.068 ; \mathrm{SRMR}=.053 ; \mathrm{AICc}=36816.94 ; \mathrm{aBIC}=36876.114)$ and bifactor solution $(\mathrm{CFI}$ $=.969 ; \mathrm{TLI}=.959, \mathrm{RMSEA}=.051 ; \mathrm{SRMR}=.034 ; \mathrm{AICc}=36622.53 ; \mathrm{aBIC}=36687.936)$, respectively, when using mother reported data. In general, the bifactor model fit the data better than a correlated-traits model: Sample 1 (validation): $\Delta \mathrm{CFI}=.042 ; \Delta \mathrm{TLI}=.030 ; \Delta \mathrm{RMSEA}=-$ $0.008 ; \Delta \mathrm{SRMR}=-0.012, \Delta \mathrm{AICc}=-3.05 ; \Delta \mathrm{aBIC}=-29.913 ;$ Sample $2($ child report $): \Delta \mathrm{CFI}=$ $.029 ; \Delta \mathrm{TLI}=.020 ; \Delta \mathrm{RMSEA}=-0.005 ; \Delta \mathrm{SRMR}=-0.012 ; \Delta \mathrm{AICc}=136.46 ; \Delta \mathrm{aBIC}=-39.367 ;$ and Sample 2 (mother report): $\Delta \mathrm{CFI}=.03 ; \Delta \mathrm{TLI}=.031 ; \Delta \mathrm{RMSEA}=-0.017 ; \Delta \mathrm{SRMR}=-0.0190$; $\Delta \mathrm{AICc}=-194.41 ; \Delta \mathrm{aBIC}=-188.178$.

\section{Measurement Invariance of the HSC-21 Scale}

Next, measurement invariance of the HSC-21 was tested across multiple groups. Regarding gender and developmental stage, results (Table 4) showed evidence for a full configural, partial metric (one item was variant with higher factor loading for girls), and full scalar invariance across gender in Sample 1. In Sample 2, evidence was found for full configural, full metric, and full scalar invariance across gender and developmental stage. Regarding measurement invariance across Belgium and the Netherlands, results (Table 4) showed evidence for full configural, full metric, and partial scalar invariance (one item was variant with higher intercepts in the Dutch sample). Finally, regarding measurement invariance across informants, results (Table 4) supported full configural invariance, partial metric invariance (one variant item with higher factor loadings for mother reports), and partial scalar invariance (with most variant items, except items HSC11 and 13, having higher intercepts for mother reports in comparison to child reports). 


\section{Internal Consistency and Dimensionality of the HSC-21 Scale}

The internal consistency values of the item scores on all subscales of the HSC-21 were good across Sample 1 and 2 and across child and mother reports (Table 5). The internal consistency values of the scores on the original 12 items are added for informational purposes, but cannot be directly compared due to differences in the number of items. Bifactor specific indices were further examined. Omega hierarchical of the general factor $\left(\omega_{\mathrm{H}}\right)$ indicated that 37 to $54 \%$ of the total variance of the HSC items in Sample 1 and Sample 2 (child report), and Sample 2 (mother report), respectively, were due to the general sensitivity factor while controlling for the specific sensitivity factors (EOE-LST and AES). When comparing $\omega_{\mathrm{H}}$ and $\omega$, results indicated that 29 to $40 \%$ of the reliable variance in the total sensitivity scores was due to the subscale scores (EOE-LST and AES). For the specific factors, we see that 63 to $65 \%$ of the total variance of the HSC items in Sample 1 and 2 was explained by the EOE-LST factor and 29 to $53 \%$ by the AES specific factor when controlling for the variance in HSC items explained by the general factor. By comparing $\omega_{\mathrm{S}}$ with $\omega$ of the specific factors, EOE-LSTresults indicated that 16 to $29 \%$ of the reliable variance in the EOE-LST subscale scores and 36 to $48 \%$ of the reliable variance in AES subscale scores were accounted for by the total sensitivity score.

\section{Descriptive Statistics and Agreement Between Child and Mother Reports}

Information on the descriptive statistics and the intercorrelations among the subscales of the HSC-21 scale are presented in Table 6 (Sample 1) and Table 7 (Sample 2; descriptive statistics of the original 12 items were added for informative and comparison purposes). Results across the different samples showed small to moderate positive correlations between the EOELST and AES subscales. By comparing the mean scores on the total and subscales of the HSC-21 with their original counterparts, large positive correlations were found. Moreover, the scores on 
the HSC-21 total scale and subscales were relatively normally distributed whereas this was not the case for the original items (i.e., skewness values are more around zero for the HSC-21 in comparison to the HSC-12, see Table 6 and 7). The median of the HSC-21 total and subscales was also close to the middle of the theoretical range, compared to the median of the 12-item version (e.g., the median of the AES subscale [Sample 1] indicated that $50 \%$ of the responses were between 5.75 and 7, whereas the other 50\% were between 1 and 5.75). Because (partial) scalar measurement invariance was established, we could compare the correlations between child and mother reports (Table 7). Results indicated medium positive correlations between child and mother reports on the EOE-LST subscale, and a low non-significant positive correlation between child and mother reports on the items of the AES subscale. As an additional analysis, the agreement between mother and child reports at item-level was investigated. Results indicated that across most items of EOE-LST (especially items regarding being easily overwhelmed and sensitivity to loud noises and pain), there were medium positive correlations between child and mother reports (Table S3). For AES, items regarding noticing details in the environment and the importance of how food tastes, showed small positive correlations between child and mother reports, whereas mother and child reports on other items did not significantly correlate (i.e., items regarding having a delicate sense of smell, distinguishing different tastes, and having an eye for details in the environment).

\section{Convergent and Discriminant Validity: The Association of the HSC-21 with Well-Studied Domains of Personality and Temperament}

Bivariate zero-order and partial correlations between the HSC-21 scales and well-studied domains of personality and temperament were investigated (Table 8). Results showed positive correlations between the scores on the HSC-total scale and scores on Neuroticism, Negative 
affect, and Orienting sensitivity, and negative associations with Extraversion (temperament), Extraversion (personality, Sample 2), Agreeableness (Sample 2), and Effortful control (Sample 2). For the subscales of HSC-21, we describe only partial correlations because they control for the contribution of the other sensitivity subscale. Regarding the scores on the EOE-LST subscale, results across samples showed positive correlations with Negative affect, Orienting sensitivity, and Neuroticism (Sample 2); and negative associations with Conscientiousness, Extraversion (temperament), Extraversion (personality, Sample 2), Openness (Sample 2), Agreeableness (Sample 2), and Effortful control (Sample 2). Scores on the AES subscale showed positive correlations with Openness, Orienting Sensitivity (Sample 2), and Extraversion (temperament and personality).

\section{Criterion Validity: The HSC-21 as a Moderator of Environmental Stimuli}

Results of the eight hierarchical regression analyses are shown in Table 9 (total HSC scale) and 10 (HSC subscales). VIF was around 1 across all analyses, indicating evidence for no

multicollinearity. Across both samples no evidence for the moderating role of the HSC-21 in the relationship between parenting and internalizing and externalizing problem behaviors was found. Results suggested only some direct associations with HSC-21 total scale and subscales. Higher scores on environmental sensitivity, especially on EOE-LST, were associated with more externalizing and internalizing problem behaviors.

\section{Discussion}

Individual differences in environmental sensitivity in children and adolescents can be measured with the Highly Sensitive Child (HSC) scale (Pluess et al., 2018; Weyn et al., 2019). The original HSC scale shows a bifactor structure with a general sensitivity factor and three group factors (i.e., Ease of Excitation [EOE], Low Sensory Threshold [LST], and Aesthetic 
Sensitivity [AES]). However, previous studies (e.g., Weyn et al., 2019) indicated that (a) the internal consistency values of the scores on two out of three subscales (i.e., LST and AES) were too low in the examined samples, (b) there was low variation in responses on some items (due to ceiling effects), (c) the scope of the domains captured by the items (i.e., content validity) was limited, and (d) the HSC scale was only partially metric and scalar invariant across developmental stage (i.e., early versus middle to late adolescents), gender, and country (i.e., Belgium and the UK). Therefore, in the present study we aimed to improve the HSC scale by developing and testing additional items $(n=26)$ that were expected to perform better than the original 12 items (i.e., allowing more variation in responses and capturing the underlying construct more broadly).

\section{Item Selection, Factor Structure, Measurement Invariance, and Multi-Informant Agreement of the HSC-21 Scale}

By using Hull method, ESEM, MIRT, and theoretical considerations, 21 items loading on two dimensions (EOE-LST and AES) were selected. The model fit of a two-factor correlated traits model and a bifactor model with the same two first-order factors were examined across a Belgian and a Dutch sample, including child and mother reports. Evidence pointed to the bifactor solution with a general sensitivity factor and two specific factors (i.e., EOE-LST and AES) as the most optimal configuration. Therefore, we recommend that researchers examine both the general sensitivity factor (i.e., more or less sensitivity) and the two specific factors. We believe that this will contribute to a better understanding of the environmental sensitivity construct and allows researchers to characterize individual children in terms of sensitivity along the different dimensions on top of the general sensitivity dimension. In contrast to the original HSC scale, we collapsed two factors (i.e., EOE and LST) into one factor (i.e., EOE-LST). Previous studies 
supported a bifactor solution with three specific factors (i.e., EOE, LST, and AES), but found that EOE and LST showed large mutual associations and similar associations with external variables, such as personality and temperament (Pluess et al., 2018; Weyn et al., 2019). These studies indicated that higher scores on EOE and LST might be associated with a sensitivity towards negative environments, whereas higher scores on AES might be associated with a sensitivity towards positive environments (Pluess et al., 2018; Weyn et al., 2019). Moreover, Evans and Rothbart (2008) also found in adults most evidence for a factor solution of the Highly Sensitive Person (HSP) scale (i.e., the adult variant of the HSC scale) with two orthogonal factors: (a) Negative Affect which is associated with temperamental traits Negative Affect and more specifically with Sensory Discomfort and (b) Orienting Sensitivity which is associated with the temperamental traits Orienting Sensitivity/Openness and its subscale Sensory Sensitivity.

Therefore, the final factor structure that we present in the present study is supported by the results across multiple analyses and samples, is partially in line with results of previous studies, is more parsimonious than the original structure, and is meaningful when we look at associations with external variables (e.g., temperament and personality).

Regarding measurement invariance, evidence was found for full configural, partial (Sample 1, one invariant item) and full (Sample 2) metric invariance, and full scalar invariance across gender and developmental stage (i.e., children in primary versus secondary school). A previous study, investigating the psychometric properties of the original scale across different samples, supported evidence for only partial metric and partial scalar invariance across gender and developmental stage (with multiple variant items; Weyn et al., 2019). Next, evidence was found for full configural, full metric, and partial scalar invariance (one variant item) across the Belgian and Dutch sample. Finally, evidence was found for full configural, partial metric, and partial scalar invariance across mother and self-reports. These results mean that (a) the 
underlying structure of environmental sensitivity was conceptualized similarly across the investigated groups (i.e., configural invariance), (b) children and early adolescents, boys and girls, from both samples attributed the same meaning to environmental sensitivity (i.e., metric invariance, with the exception of one variant item across all comparisons), and (c) children and early adolescents from both samples used the same reference point (with the exception of variant items; i.e., partial scalar invariance). In general, non-invariant items per analysis showed higher associations (i.e., factor loadings) for girls in comparison to boys, a higher reference point (i.e., intercept) in the Dutch sample in comparison to the Belgian sample, and a higher reference point and higher associations (i.e., factor loading) for mother-reports in comparison to child-reports. For the group comparisons in which full scalar measurement was established (i.e., developmental stage and gender), researchers are allowed to compare the observed means (Van de Schoot et al., 2012). For the other comparisons, where only partial scalar invariance was established, it is possible to compare the latent structure, latent mean levels, inter-correlations, and predictive relations with external variables of the HSC-21 across Belgium and the Netherlands and across child and mother reports (Steinmetz, 2013).

We were able to investigate the agreement between child and mother reports, because partial scalar measurement invariance between informants was established. Results showed moderate associations between child and mother reports on the total scale and EOE-LST dimension, but not for AES. These results are in line with research on agreement between children and mothers regarding personality traits (Laidra et al., 2006). Research showed moderate agreement between children and mothers for Neuroticism, Extraversion, and Agreeableness (which seems to be associated with EOE-LST; e.g., Weyn et al., 2019), but only low agreement between child and mother reports for Openness (which seems to be associated with AES; e.g., Weyn et al., 2019). 


\section{Internal Consistency, Dimensionality, and Distribution of the HSC-21}

Results showed good internal consistency values of the scores on the total scale and subscales across the different samples. Bifactor model specific indices (i.e., McDonald's hierarchical omega of the group factor and specific factors and ECV) were examined to further explore the psychometric properties of the HSC-21. The hierarchical omega indices indicated that both the general sensitivity factor and the specific factors explained a considerable amount of variance in the data, also after controlling for each other's contribution. The ECV, an index of unidimensionality, also supported a multidimensional structure. In a previous study, the variance explained by the general factor was almost exclusively attributed to the variance explained by EOE and LST (Weyn et al., 2019). Using the HSC-21, both the AES and EOE-LST scales contribute to the variance explained by the general factor. In addition, item scores on all the scales (i.e., total scale and subscales) were distributed relatively normally and the formulation of the items allowed more variation in responses.

\section{Convergent, Discriminant, and Criterion Validity}

Across both samples, EOE-LST showed small to medium (Sample 1) and large (Sample 2) associations with Neuroticism, Negative Affect, and Orienting Sensitivity, whereas AES showed small to medium positive associations with Extraversion (only Sample 2) and Openness and a large positive association with Orienting Sensitivity (Sample 2). These results are in line with previous research (e.g., Aron \& Aron, 1997; Pluess et al., 2018; Smolewska et al., 2006; Weyn et al., 2019), which showed that environmental sensitivity is related to (i.e., convergent validity), but not simply a reflection of (i.e., discriminant validity) well-studied domains of temperament (e.g., the model of Evans and Rothbart (2008)) and personality (e.g., Big Five; (McCrae \& Costa, 1987)). Moreover, they indicated that the different dimensions (EOE and LST 
versus AES) were differently related to domains of personality and temperament, with EOE and LST showing medium associations with Neuroticism and Negative affect, and AES showing small to medium associations with Openness and Extraversion (Pluess et al., 2018).

Regarding criterion validity, based on the environmental sensitivity framework (Pluess, 2015) we would expect that children scoring high on the HSC scale are more affected by both positive and negative environmental stimuli. However, results did not show evidence for the HSC-21 (total scale and subscales) as a moderator in the relationship between supportive and/or psychological controlling parenting and internalizing and externalizing problem behaviors. Previous studies (e.g., Lionetti et al., 2019; Slagt et al., 2018) did find evidence for a heightened sensitivity towards positive and negative environments (i.e., differential susceptibility). These studies differed from the present study in that they studied much younger children (i.e., toddlers) and used a different design (e.g., longitudinal study, observation study, or specified environmental sensitivity as a categorical predictor). Moreover, because we examined general population samples, we were not able to see much variation in parenting and outcome measures. Most parents reported high supportive parenting, low psychological controlling parenting, and low internalizing and externalizing problem behaviors. Finally, it is possible that there are better proxies of environmental quality in adolescence than parent reported positive and negative parenting, such as family climate, friendship quality, socioeconomic status, difficulties in coparenting, and major life events.

\section{Strengths, Limitations, and Further Research}

An important strength is the in-depth examination of the psychometric properties of an improved version of the HSC scale in two different samples, including both child and mother reports and reports from two different countries (i.e., Belgium and the Netherlands). The present 
study created a parent-report version of the HSC-21 and was the first to examine agreement between child and mother reports. Across these samples, the HSC-21 showed acceptable to good psychometric properties and a moderate agreement between child and mother reports on environmental sensitivity. However, there are also some limitations. First, all findings were based on self and mother reports, which may elicit socially desirable answers. It could be informative to also include father and teacher reports, or to use more objective measures such as observations or experimental manipulations (e.g., positive mood induction). Second, we used Belgian and Dutch samples that are both predominantly Caucasian and are quite similar to each other (e.g., Dutch language). It would be interesting to compare our findings with findings in more ethnically diverse samples to examine the culture fair nature of the HSC-21 and environmental sensitivity in general. Third, for AES we found little agreement between child and mother reports. It would be interesting in further research to investigate possible predictors (e.g., differences in personality/temperament of the informant) and outcomes (e.g., self-esteem) that are associated with little agreement between child and mother reports on environmental sensitivity. Fourth, the current study is cross-sectional, therefore we were not able to examine whether the HSC-21 interacts with changes in positive and negative parenting or to investigate the direction of associations between parenting and environmental sensitivity across time. Fifth, as a proxy of environmental quality, we included only parent reported parenting, for which there was not much variation in responses (i.e., most parents reported high support and low psychological control). Sixth, externalizing problem behavior was measured with different questionnaires, which makes a direct comparison of the results between both samples difficult. Seventh, because of the smaller sample size of self-reported data in Sample 2, we were not able to use these data across all analyses. Finally, a shortcoming of all existing HSC (children) and HSP (adults) scales is that they do not capture depth of cognitive processing. We tried to include some items capturing the 
pause and check behaviors as observed in highly sensitive children (Items 16 and 34 in

Supplementary Material 1, Lionetti et al., 2019), but during data collection we noticed that these items were too difficult for children to answer. This issue of content validity and item wording appropriateness for younger children should be taken into account in further research.

Nevertheless, we believe that the HSC-21 captures the different dimensions of environmental sensitivity in a more fine-grained way than previous measures (e.g., more sensory modalities and with items that discriminate more among people along the continuum of environmental sensitivity).

\section{Conclusion}

The present study described the development and initial validation of the Highly Sensitive Child-21 items scale (HSC-21). The HSC-21 is an adaptation of the original Highly Sensitive Child scale with additional items that perform better than the original ones. Results across different samples, including Belgian and Dutch samples and child and mother reports, showed acceptable to good psychometric properties of the HSC-21. The HSC-21 showed (a) an acceptable to good model fit of a bifactor model with a general sensitivity factor and two specific factors: the first one is ease of excitation and low sensory threshold (EOE-LST) and the second one refers to aesthetic sensitivity (AES), (b) (partial) measurement invariance across gender, developmental stage, country, and informants, (c) good reliability, (d) 21 informative items that are relatively normal distributed and allowing variation in responses, (e) moderate agreement between child and mother reports, and (f) meaningful associations with well-studied domains of temperament and personality. However, no evidence was found for the moderating role of the HSC-21 between parenting and internalizing and externalizing problem behaviors. Based on the present study, we recommend to use the HSC-21 when (a) investigating the different dimensions 
of environmental sensitivity (i.e., EOE-LST and AES), (b) using both child and mother reports, or (c) characterizing individual children in terms of sensitivity along the different dimensions.

When one is interested in the construct in general and in its moderating role both the HSC-12 and HSC-21 can be used. The HSC-21 can be used in further research and eventually also in clinical practice or in school contexts to develop more personalized interventions.

\section{Methodological Disclosure}

We report how we determined our sample size, all data exclusions, all manipulations, and all measures in the study. 


\section{References}

Achenbach, T. M. (1991a). Manual for the Child Behavior Checklist/4-18 and 1991 profile. University of Vermont.

Arbuckle, J. L. (1996). Full information estimation in the presence of incomplete data. In G. A. Marcoulides \& R. E. Schumacker (Eds.), Advanced structural equation modeling: Issues and Techniques (pp. 243-277). Lawrence Erlbaum Associates.

Aron, E. N., \& Aron, A. (1997). Sensory-processing sensitivity and its relation to introversion and emotionality. Journal of Personality and Social Psychology, 73(2), 345-368. https://doi.org/10.1037/0022-3514.73.2.345

Asparouhov, T., \& Muthén, B. (2009). Exploratory structural equation modeling. Structural Equation Modeling: A Multidisciplinary Journal, 16(3), 397-438. https://doi.org/10.1080/10705510903008204

Baker, F. (2001). The basics of item response theory (2nd ed.). ERIC Clearinghouse on Assessment and Evaluation.

Belsky, J., \& Pluess, M. (2009). Beyond diathesis stress: Differential susceptibility to environmental influences. Psychological Bulletin, 135(6), 885-908. https://doi.org/10.1037/a0017376

Boateng, G. O., Neilands, T. B., Frongillo, E. A., Melgar-Quiñonez, H. R., \& Young, S. L. (2018). Best practices for developing and validating scales for health, social, and behavioral research: A primer. Frontiers in public health, 6, 149-149. https://doi.org/10.3389/fpubh.2018.00149

Booth, T., \& Hughes, D. J. (2014). Exploratory structural equation modeling of personality data. Assessment, 21(3), 260-271.

Brown, T. A. (2015). Confirmatory factor analysis for applied research 2 nd ed. Guilford Press. 
Burnham, K. P., \& Anderson, D. R. (2004). Multimodel inference: Understanding AIC and BIC in model selection. Sociological Methods \& Research, 33(2), 261-304. https://doi.org/10.1177/0049124104268644

Byrne, B. M., Shavelson, R. J., \& Muthén, B. (1989). Testing for the equivalence of factor covariance and mean structures: The issue of partial measurement invariance. Psychological Bulletin, 105(3), 456.

Caspi, A., Sugden, K., Moffitt, T. E., Taylor, A., Craig, I. W., Harrington, H., McClay, J., Mill, J., Martin, J., Braithwaite, A., \& Poulton, R. (2003). Influence of life stress on depression: Moderation by a polymorphism in the 5-HTT gene. Science, 301(5631), 386-389. https://doi.org/10.1126/science.1083968

Chen, F. F. (2007). Sensitivity of goodness of fit indexes to lack of measurement invariance. Structural Equation Modeling: A Multidisciplinary Journal, 14(3), 464-504. https://doi.org/10.1080/10705510701301834

Cohen, J. (1988). Statistical Power Analysis for the Behavioral Sciences. Routledge Academic.

Dunn, T. J., Baguley, T., \& Brunsden, V. (2014). From alpha to omega: A practical solution to the pervasive problem of internal consistency estimation. British Journal of Psychology, 105(3), 399-412. https://doi.org/10.1111/bjop.12046

El-Sheikh, M., Keller, P. S., \& Erath, S. A. (2007). Marital conflict and risk for child maladjustment over time: Skin conductance level reactivity as a vulnerability factor [journal article]. Journal of Abnormal Child Psychology, 35(5), 715-727. https://doi.org/10.1007/s10802-007-9127-2

Evans, D. E., \& Rothbart, M. K. (2007). Developing a model for adult temperament. Journal of Research in Personality, 41(4), 868-888. 
Evans, D. E., \& Rothbart, M. K. (2008). Temperamental sensitivity: Two constructs or one? Personality and Individual Differences, 44(1), 108-118. https://doi.org/10.1016/j.paid.2007.07.016

Gomes, C. M. A., Almeida, L. S., \& Núñez, J. C. (2017). Rationale and applicability of exploratory structural equation modeling (ESEM) in psychoeducational contexts. Psicothema, 29(3), 396-401.

Goodman, R. (1997). The strengths and difficulties questionnaire: A research note. Journal of Child Psychology and Psychiatry, 38(5), 581-586. https://doi.org/doi:10.1111/j.14697610.1997.tb01545.x

Greven, C. U., Lionetti, F., Booth, C., Aron, E. N., Fox, E., Schendan, H. E., Pluess, M., Bruining, H., Acevedo, B., Bijttebier, P., \& Homberg, J. (2019). Sensory Processing Sensitivity in the context of Environmental Sensitivity: A critical review and development of research agenda. Neuroscience and Biobehavioral Reviews, 98, 287-305. https://doi.org/10.1016/j.neubiorev.2019.01.009

Immekus, J. C., Snyder, K., \& Ralston, P. A. (2019). Multidimensional item response theory for factor structure assessment in educational psychology research. Frontiers in Education, 4, 45. https://doi.org/ https://doi.org/10.3389/feduc.2019.00045

Kline, R. B. (2005). Principles and practice of structural equation modeling (2nd ed.). Guilford Press.

Laidra, K., Allik, J., Harro, M., Merenäkk, L., \& Harro, J. (2006). Agreement among adolescents, parents, and teachers on adolescent personality. Assessment, 13(2), 187-196. https://doi.org/10.1177/1073191106287125

Leary, M. R. (2008). Introduction to behavioral research methods (5th ed.). Pearson Education 
Lionetti, F., Aron, A., Aron, E. N., Burns, G. L., Jagiellowicz, J., \& Pluess, M. (2018).

Dandelions, tulips and orchids: Evidence for the existence of low-sensitive, mediumsensitive and high-sensitive individuals. Translational Psychiatry, 8(1), 24. https://doi.org/10.1038/s41398-017-0090-6

Lionetti, F., Aron, E. N., Aron, A., Klein, D. N., \& Pluess, M. (2019). Observer-rated environmental sensitivity moderates children's response to parenting quality in early childhood. Developmental Psychology, 55(1), 2389-2402.

https://doi.org/https://doi.org/10.1037/dev0000795

Little, R. J. A. (1988). A test of missing completely at random for multivariate data with missing values. Journal of the American Statistical Association, 83(404), 1198-1202. https://doi.org/10.1080/01621459.1988.10478722

Lorenzo-Seva, U., Timmerman, M. E., \& Kiers, H. A. (2011). The Hull method for selecting the number of common factors. Multivariate Behavioral Research, 46(2), 340-364.

Marsh, H. W., Morin, A. J. S., Parker, P. D., \& Kaur, G. (2014). Exploratory structural equation modeling: An integration of the best features of exploratory and confirmatory factor analysis. Annual Review of Clinical Psychology, 10(1), 85-110. https://doi.org/10.1146/annurev-clinpsy-032813-153700

McCrae, R. R., \& Costa, P. T. (1987). Validation of the five-factor model of personality across instruments and observers. Journal of Personality and Social Psychology, 52(1), 81.

McDonald, R. P. (1999). Test theory: A unified treatment. Erlbaum.

Menard, S. (1995). Applied Logistic Regression Analysis: Sage University Series on Quantitative Applications in the Social Sciences. Sage. 
Mervielde, I., De Fruyt, F., \& De Clercq, B. (2009). HiPIC: Hiërarchische Persoonlijkheidsvragenlijst voor Kinderen. [HiPIC: Hierarchical personality questionnaire for children]. Hogrefe.

Nocentini, A., Menesini, E., \& Pluess, M. (2018). The personality trait of environmental sensitivity predicts children's positive response to school-based antibullying intervention. Clinical Psychological Science, 6(6), 848-859. https://doi.org/10.1177/2167702618782194

Osteen, P. (2010). An introduction to using multidimensional item response theory to assess latent factor structures. Journal of the Society for Social Work and Research, 1(2), 66-82. https://doi.org/10.5243/jsswr.2010.6

Pluess, M. (2015). Individual differences in environmental sensitivity. Child Development Perspectives, 9(3), 138-143. https://doi.org/10.1111/cdep.12120

Pluess, M., Assary, E., Lionetti, F., Lester, K. J., Krapohl, E., Aron, E., \& Aron, A. (2018). Environmental sensitivity in children: Development of the Highly Sensitive Child scale and identification of sensitivity groups. Developmental Psychology, 54(1), 51-70. https://doi.org/10.1037/dev0000406

Pluess, M., \& Boniwell, I. (2015). Sensory-processing sensitivity predicts treatment response to a school-based depression prevention program: Evidence of vantage sensitivity. Personality and Individual Differences, 82, 40-45. https://doi.org/10.1016/j.paid.2015.03.011

Raftery, A. E. (1995). Bayesian model selection in social research. Sociological Methodology, 25, 111-163. https://doi.org/10.2307/271063

Reckase, M. D. (2009). Multidimensional Item Response Theory. Springer https://books.google.be/books?id=OdL9BIOpWEEC 
Revelle, W., \& Zinbarg, R. E. (2008). Coefficients alpha, beta, omega, and the glb: Comments on Sijtsma. Psychometrika, 74(1), 145. https://doi.org/10.1007/s11336-008-9102-z

Rigdon, E. E. (1996). CFI versus RMSEA: A comparison of two fit indexes for structural equation modeling. Structural Equation Modeling: A Multidisciplinary Journal, 3(4), 369-379. https://doi.org/10.1080/10705519609540052

Rodriguez, A., Reise, S. P., \& Haviland, M. G. (2015). Evaluating bifactor models: Calculating and interpreting statistical indices. Psychological Methods, 21(2), 137.

Satorra, A., \& Bentler, P. M. (1994). Corrections to test statistics and standard errors in covariance structure analysis. In A. V. Eye \& C. C. Clogg (Eds.), Latent variables analysis: Applications for developmental research (pp. 399-419). Sage.

Schmitt, N., Golubovich, J., \& Leong, F. T. (2011). Impact of measurement invariance on construct correlations, mean differences, and relations with external correlates: An illustrative example using Big Five and RIASEC measures. Assessment, 18(4), 412-427. https://doi.org/10.1177/1073191110373223

Sellbom, M., \& Tellegen, A. (2019). Factor analysis in psychological assessment research: Common pitfalls and recommendations. Psychological Assessment, 31(12), 1428-1441. https://doi.org/http://dx.doi.org/10.1037/pas0000623

Sharkness, J., \& DeAngelo, L. (2011). Measuring student involvement: A comparison of classical test theory and item response theory in the construction of scales from student surveys. Research in Higher Education, 52(5), 480-507. https://doi.org/10.1007/s11162-010-9202$\underline{3}$

Sijtsma, K. (2008). On the use, the misuse, and the very limited usefulness of Cronbach's alpha. Psychometrika, 74(1), 107. https://doi.org/10.1007/s11336-008-9101-0 
Slagt, M., Dubas, J. S., van Aken, M. A. G., Ellis, B. J., \& Dekovic, M. (2018). Sensory processing sensitivity as a marker of differential susceptibility to parenting. Devopmental Psychology, 54(3), 543-558. https://doi.org/10.1037/dev0000431

Smolewska, K. A., McCabe, S. B., \& Woody, E. Z. (2006). A psychometric evaluation of the Highly Sensitive Person Scale: The components of sensory-processing sensitivity and their relation to the BIS/BAS and "Big Five". Personality and Individual Differences, 40(6), 1269-1279. https://doi.org/10.1016/j.paid.2005.09.022

Soenens, B., Vansteenkiste, M., Luyckx, K., \& Goossens, L. (2006). Parenting and adolescent problem behavior: An integrated model with adolescent self-disclosure and perceived parental knowledge as intervening variables. Developmental Psychology, 42(2), 305-318. https://doi.org/10.1037/0012-1649.42.2.305

Steinmetz, H. (2013). Analyzing observed composite differences across groups: Is partial measurement invariance enough? Methodology: European Journal of Research Methods for the Behavioral and Social Sciences, 9(1), 1-12. https://doi.org/10.1027/1614$\underline{2241 / a 000049}$

Van de Schoot, R., Lugtig, P., \& Hox, J. (2012). A checklist for testing measurement invariance. European Journal of Developmental Psychology, 9(4), 486-492. https://doi.org/10.1080/17405629.2012.686740

Van Leeuwen, K., Vermulst, A., Kroes, G., De Meyer, R., \& Veerman, J. W. (2018). Handleiding VSOG. Verkorte Schaal voor Ouderlijk Gedrag. [Brief Scale of Parental Behavior]. Praktikon BV.

Weyn, S., Van Leeuwen, K., Pluess, M., Lionetti, F., Greven, C. U., Goossens, L., Colpin, H., Van Den Noortgate, W., Verschueren, K., Bastin, M., Van Hoof, E., De Fruyt, F., \& Bijttebier, P. (2019). Psychometric properties of the Highly Sensitive Child scale across 
developmental stage, gender, and country. Current Psychology, 1-17. https://doi.org/10.1007/s12144-019-00254-5

Zinbarg, R. E., Revelle, W., Yovel, I., \& Li, W. (2005). Cronbach's $\alpha$, Revelle's $\beta$, and Mcdonald's $\omega \mathrm{H}$ : Their relations with each other and two alternative conceptualizations of reliability. Psychometrika, 70(1), 123-133. https://doi.org/10.1007/s11336-003-0974-7 
HIGHLY SENSITIVE CHILD SCALE 21-ITEM VERSION

\section{Figures}

Figure 1. Bifactor Model of the Original Highly Sensitive Child Scale 


\section{Figures}

\section{Figure 1}

\section{Bifactor Model of the Original Highly Sensitive Child Scale}

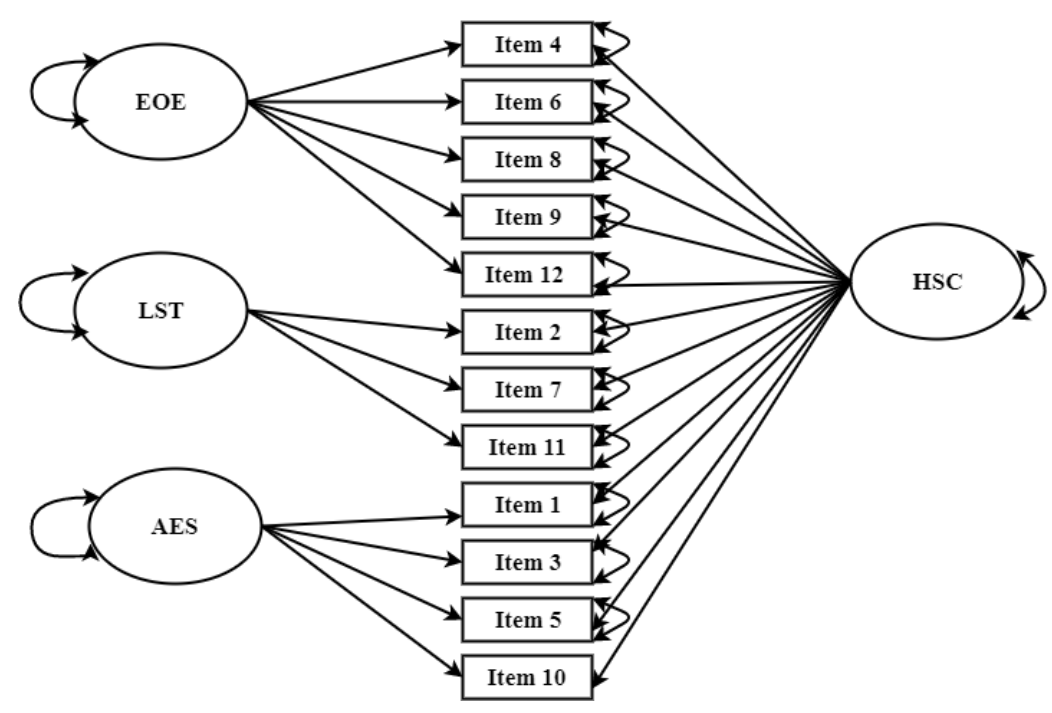

Note. HSC = Highly Sensitive Child; EOE = Ease of Excitation; LST = Low Sensory Threshold: AES = Aesthetic Sensitivity. From: "Weyn, S., Van Leeuwen, K., Pluess, M., Lionetti, F., Greven, C. U., Goossens, L., Colpin, H., Van Den Noortgate, W., Verschueren, K., Bastin, M., Van Hoof, E., De Fruyt, F., \& Bijttebier, P. (2019). Psychometric properties of the Highly Sensitive Child scale across developmental stage, gender, and country. Current Psychology, 1-17. https://doi.org/10.1007/s12144-019-00254-5 
Tables

\section{Table 1}

Descriptive Statistics and Internal Consistency Values of the Different Variables With the Exception of Environmental Sensitivity (See Further)

in Sample 1 and 2.

\begin{tabular}{lcccccccccc}
\hline Scale & \multicolumn{3}{c}{ Sample 1} & \multicolumn{7}{c}{ Sample 2} \\
\cline { 2 - 9 } & $M(S D)$ & Min & Max & $\alpha$ & $M(S D)$ & Min & Max & $\alpha$ \\
\hline Personality & & & & & & & & \\
Emotional stability (opposite of neuroticism) & $2.69(0.80)$ & 1.00 & 5.00 & .91 & $2.97(0.73)$ & 1.31 & 5.00 & .92 \\
Extraversion & $3.62(0.51)$ & 1.56 & 4.82 & .90 & $3.46(0.57)$ & 1.56 & 4.69 & .92 \\
Imagination (openness) & $3.87(0.55)$ & 2.17 & 5.00 & .91 & $3.80(0.57)$ & 1.88 & 4.96 & .91 \\
Benevolence (agreeableness) & $3.90(0.51)$ & 2.44 & 5.00 & .94 & $3.50(0.55)$ & 1.85 & 4.60 & .95 \\
Conscientiousness & $3.35(0.66)$ & 1.31 & 4.88 & .94 & $3.29(0.60)$ & 1.50 & 4.72 & .93 \\
Temperament & & & & & & & & \\
Negative affect & & & & & & & & \\
Effortful control & $3.34(0.72)$ & 1.60 & 5.81 & .84 & $3.93(0.92)$ & 1.69 & 7.00 & .89 \\
Extraversion & $4.51(0.87)$ & 1.95 & 6.84 & .86 & $3.82(1.04)$ & 1.26 & 6.58 & .89 \\
Orienting sensitivity & $4.98(0.64)$ & 2.71 & 6.47 & .71 & $4.67(0.80)$ & 2.24 & 6.82 & .78 \\
& $3.86(0.89)$ & 1.79 & 6.50 & .81 & $4.01(0.91)$ & 1.93 & 6.73 & .83
\end{tabular}

Parenting 


\begin{tabular}{lccccccccc}
\hline Scale & \multicolumn{3}{c}{ Sample 1 } & \multicolumn{5}{c}{ Sample 2 } \\
\cline { 2 - 9 } & $M(S D)$ & Min & Max & $\alpha$ & $M(S D)$ & Min & Max & $\alpha$ \\
\hline Positive parenting & $4.39(0.46)$ & 2.88 & 5.00 & .83 & $4.45(0.40)$ & 3.00 & 5.00 & .78 \\
Negative parenting & $1.92(0.48)$ & 1.00 & 4.73 & .83 & $1.58(0.43$ & 1.00 & 3.50 & .73 \\
Externalizing problem behavior & $0.17(0.16)$ & 0.00 & 0.89 & .87 & $1.61(0.41)$ & 1.00 & 2.60 & .79 \\
Internalizing problem behavior & $0.24(0.20)$ & 0.00 & 1.25 & .87 & $0.31(0.27)$ & 1.00 & 2.39 & .90 \\
\hline
\end{tabular}




\section{Table 2}

Items of the Extended Version of the Highly Sensitive Child Scale (34 Items), Factor Loadings, Discrimination, and Threshold Parameters for a Two-Factor Correlated Traits Model in the Calibration Part of Sample 1

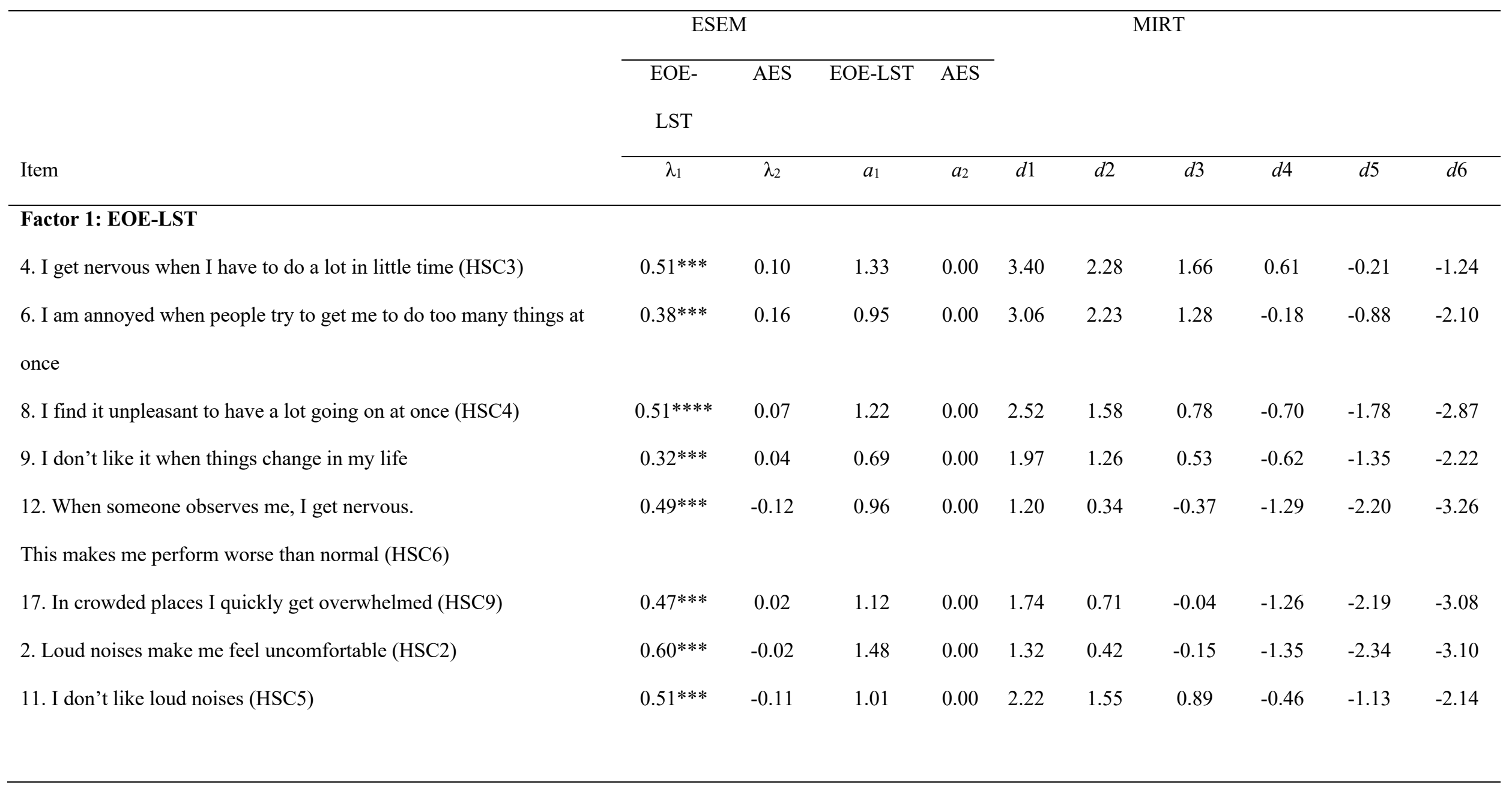




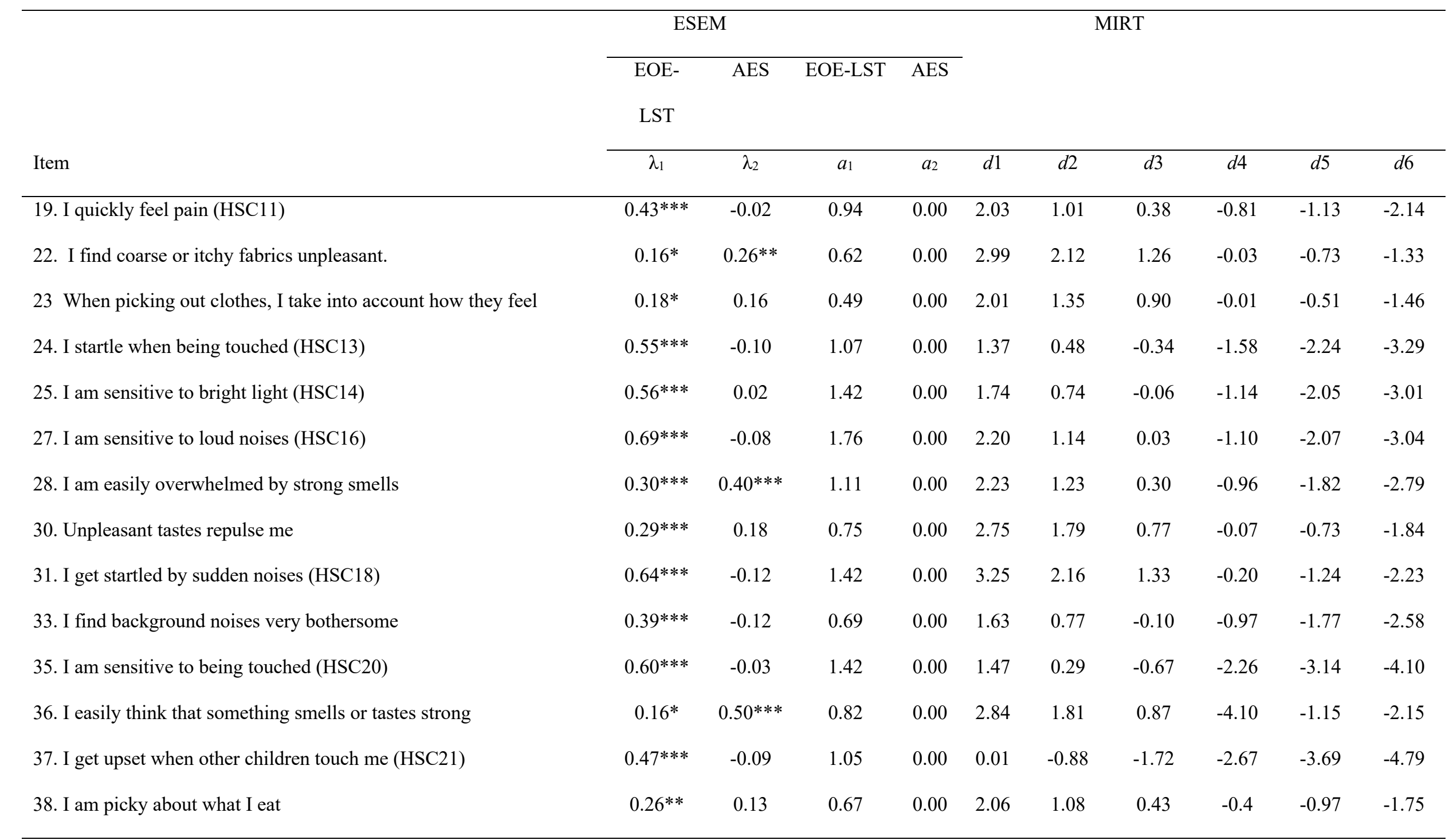


Factor 2: AES

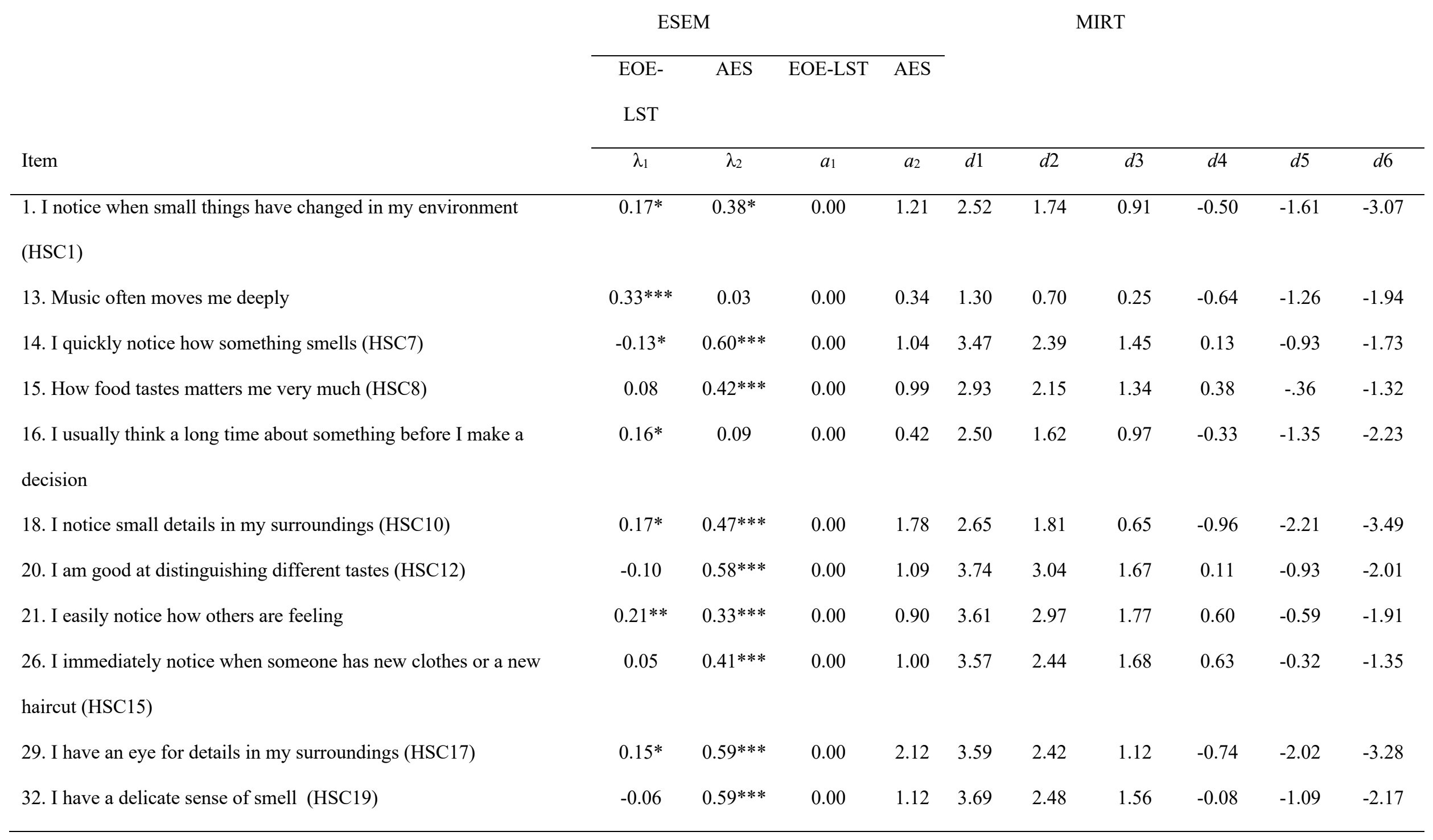


34. I use as much information around me as possible before I get

started on something

Note. HSC = Highly Sensitive Child scale total score; EOE = Ease of Excitation; LST = Low Sensory Threshold; AES = Aesthetic Sensitivity; selected items in bold; $\lambda=$ factor loading; $a=$ slope; $d=$ category boundary intercept which are ordered in a decreasing

manner. The bullet numbers are the numbers of the items of the extended HSC scale (see Supplementary Material 1). The numbers between parentheses are the item variable names of the final HSC-21 scale.

$*_{p}<.05 ; * * p<.01 ; * * * p<.001$ 


\section{Table 3}

Standardized Factor Loadings of the Final ESEM Two-Factor (Correlated Traits) Model of the HSC21 in the Calibration Part of Sample 1

\begin{tabular}{|c|c|c|}
\hline \multirow[t]{3}{*}{ Items } & EOE- & AES \\
\hline & LST & \\
\hline & $\lambda_{1}$ & $\lambda_{2}$ \\
\hline
\end{tabular}

\section{Factor 1: EOE-LST}

I get nervous when I have to do a lot in little time (HSC3)

$\begin{array}{cc}.49 * * * & .10 \\ .46 * * * & .13 \\ .50 * * * & -.12\end{array}$

When someone observes me, I get nervous.

This makes me perform worse than normal (HSC6)

In crowded places I quickly get overwhelmed (HSC9)

$\begin{array}{ll}. .49 * * * & .04 \\ .55 * * * & .07 \\ .46 * * * & -.07 \\ .41 * * * & -.02 \\ .49 * * * & -.02 \\ .60 * * * & .04 \\ .67 * * * & -.02 \\ .62 * * * & -.09 \\ .52 * * * & .04 \\ .39 * * * & -.02\end{array}$

I get upset when other children touch me (HSC21)

\section{Factor 2: AES}

I notice when small things have changed in my environment (HSC1)

I quickly notice how something smells (HSC7)

$-.13 * \quad .56^{* * *}$

How food tastes matters me very much (HSC8)

$.01 \quad .44 * * *$

I notice small details in my surroundings (HSC10)

$.15^{*} \quad .49^{* * *}$




\begin{tabular}{lcc}
\hline Items & EOE- & AES \\
& LST \\
\cline { 2 - 3 } & $\lambda_{1}$ & $\lambda_{2}$ \\
\hline I am good at distinguishing different tastes (HSC12) & $-.14^{*}$ & $.59^{* * *}$ \\
I immediately notice when someone has new clothes or a new haircut & .03 & $.41^{* * *}$ \\
(HSC15) & & \\
I have an eye for details in my surroundings (HSC17) & .10 & $.62 * * *$ \\
I have a delicate sense of smell (HSC19) & -.06 & $.51^{* * *}$ \\
\hline Note. EOE = Ease of Excitation; LST = Low Sensory Threshold; AES = Aesthetic Sensitivity & &
\end{tabular}

${ }^{*} p<.05 ; * * * p<.001$ 


\section{Table 4}

Summary of the Measurement Invariance Analyses of the HSC-21 Across Multiple Groups Within and Between Sample 1 and 2

\begin{tabular}{|c|c|c|c|c|c|c|c|c|c|}
\hline Model & CFI & RMSEA & SRMR & $\mathrm{AICc}$ & $\mathrm{aBIC}$ & $\Delta \mathrm{CFI}$ & $\triangle \mathrm{RMSEA}$ & $\triangle \mathrm{SRMR}$ & $\begin{array}{c}\text { Non-invariant } \\
\text { items }\end{array}$ \\
\hline \multicolumn{10}{|c|}{ Across gender (Sample 1) } \\
\hline Configural invariance & .941 & .040 & .046 & 47212.24 & 46528.110 & & & & \\
\hline Metric invariance & .930 & .041 & .054 & 46678.65 & 46476.464 & .011 & -.001 & .012 & \\
\hline Partial metric & .934 & .040 & .055 & 46678.65 & 46469.206 & .007 & 0 & .013 & HSC21 \\
\hline Scalar invariance & .932 & .039 & .054 & 46537.09 & 46434.398 & .002 & .001 & .001 & \\
\hline $\begin{array}{l}\text { Across gender (Samp } \\
\text { report) }\end{array}$ & & & & & & & & & \\
\hline Configural invariance & .962 & .057 & .039 & 36089.85 & 35467.213 & & & & \\
\hline Metric invariance & .963 & .053 & .050 & 35574.05 & 35384.364 & -.001 & .004 & .011 & \\
\hline Scalar invariance & .960 & .054 & .052 & 35465.20 & 35369.520 & .003 & -.001 & -.002 & \\
\hline \multicolumn{10}{|c|}{ Across developmental stage in } \\
\hline \multicolumn{10}{|c|}{ Sample 2: mother report) } \\
\hline Configural invariance & .961 & .058 & .042 & 35960.88 & 36768.787 & & & & \\
\hline Metric invariance & .961 & .055 & .048 & 35966.06 & 36690.234 & .000 & .003 & -.006 & \\
\hline
\end{tabular}




\begin{tabular}{|c|c|c|c|c|c|c|c|c|c|}
\hline Model & CFI & RMSEA & SRMR & $\mathrm{AICc}$ & $\mathrm{aBIC}$ & $\Delta \mathrm{CFI}$ & $\triangle \mathrm{RMSEA}$ & $\triangle \mathrm{SRMR}$ & $\begin{array}{c}\text { Non-invariant } \\
\text { items }\end{array}$ \\
\hline Scalar invariance & .959 & .055 & .048 & 35961.37 & 36665.448 & .002 & .000 & .000 & \\
\hline \multicolumn{10}{|c|}{ Across Belgium (Sample 1) and the } \\
\hline \multicolumn{10}{|c|}{ Netherlands (Sample 2: child } \\
\hline \multicolumn{10}{|l|}{ report): } \\
\hline Configural invariance & .932 & .047 & .041 & 58137.25 & 58236.193 & & & & \\
\hline Metric invariance & .938 & .042 & .047 & 58026.21 & 58142.335 & -.006 & .005 & -.006 & \\
\hline Scalar invariance & .924 & .045 & .049 & 58035.82 & 58151.345 & .014 & -.003 & -.002 & \\
\hline Partial scalar invariance & .929 & .044 & .048 & 58021.66 & 58137.343 & .009 & -.002 & -.001 & HSC7 \\
\hline \multicolumn{10}{|c|}{ Child versus mother report (Sample } \\
\hline \multicolumn{10}{|l|}{ 2) } \\
\hline Configural invariance & .959 & .057 & .040 & 47673.35 & 47789.129 & & & & \\
\hline Metric invariance & .941 & .064 & .056 & 47746.49 & 47867.684 & .018 & -.013 & -.016 & \\
\hline Partial metric invariance & .957 & .055 & .051 & 47608.50 & 47729.802 & .002 & .002 & -.011 & HSC18 \\
\hline Scalar invariance & .929 & .069 & .066 & 47817.61 & 47935.202 & .028 & -.014 & -.015 & \\
\hline \multirow[t]{3}{*}{ Partial scalar invariance } & .956 & .055 & .051 & 47599.33 & 47719.440 & .001 & .000 & .000 & $\mathrm{HSC} 1,2,4,5$, \\
\hline & & & & & & & & & $9,10,11,13$ \\
\hline & & & & & & & & & 16,20 \\
\hline
\end{tabular}


Note. CFI = comparative fit index; RMSEA = root mean square error of approximation; SRMR $=$ standardized root mean squared residual; AICc $=$ sample-size-corrected Akaike information criterion; aBIC $=$ sample-size-adjusted Bayesian information criterion; $\Delta=$ increment of change. 


\section{Table 5}

Internal Consistency of the Highly Sensitive Child Scale 21 Versus 12 Items

\begin{tabular}{|c|c|c|c|c|c|c|}
\hline & \multicolumn{4}{|c|}{ HSC21 } & \multicolumn{2}{|c|}{ HSC12 } \\
\hline & $\alpha$ & $\omega$ & $\omega_{\mathrm{H} / \mathrm{S}}$ & ECV & $\alpha$ & $\omega$ \\
\hline \multicolumn{7}{|c|}{ Sample 1: Child report } \\
\hline HSC & $.81,95 \%$ CI $[.79, .84]$ & $.81,95 \%$ CI $[.78, .84]$ & .41 & .37 & $.70,95 \%$ CI $[.65, .74]$ & $.71,95 \%$ CI[.66, .75] \\
\hline \multirow[t]{2}{*}{ EOE-LST } & $.81,95 \%$ CI$[.78, .83]$ & $.81,95 \%$ CI $[.78, .83]$ & .65 & .80 & EOE:.65, 95\% CI[.59, .69] & EOE: .65, 95\% CI[.60,.65] \\
\hline & & & & & LST: .57, 95\% CI[.50, 62] & LST: .59, 95\% CI[.52,.63] \\
\hline AES & $.75,95 \%$ CI[.72, .78] & $.75,95 \%$ CI[.71, .79] & .29 & .45 & $.52,95 \%$ CI $[.43, .60]$ & $.53,95 \%$ CI $[.44, .60]$ \\
\hline \multicolumn{7}{|c|}{ Sample 2: Child report } \\
\hline $\mathrm{HSC}$ & $.88,95 \%$ CI $[.84, .91]$ & $.88,95 \%$ CI $[.78, .84]$ & .48 & .41 & $.72,95 \%$ CI $[.64, .78]$ & $.73,95 \%$ CI[.64, .80] \\
\hline \multirow[t]{2}{*}{ EOE-LST } & $.88,95 \%$ CI $[.85, .90]$ & $.88,95 \%$ CI $[.85, .91]$ & .64 & .73 & EOE: .71, 95\% CI[.62,.78] & EOE:.71, 95\% CI[.62,.78] \\
\hline & & & & & LST: .57, 95\% CI[.43, 68] & LST: .81, 95\% CI[.78,.83] \\
\hline AES & $.81,95 \%$ CI $[.75, .85]$ & $.81,95 \%$ CI[.75, .86] & .33 & .42 & $.57,95 \%$ CI $[.43, .70]$ & $.57,95 \%$ CI[.43, .69] \\
\hline \multicolumn{7}{|c|}{ Sample 2: Mother report } \\
\hline HSC & $.93,95 \%$ CI $[.92, .94]$ & $.93,95 \%$ CI $[.92, .94]$ & .64 & .54 & $.85,95 \% \mathrm{CI}[.83, .87]$ & $.86,95 \%$ CI[.83,.87] \\
\hline \multirow[t]{2}{*}{ EOE-LST } & $.92,95 \%$ CI $[.91, .93]$ & $.92,95 \%$ CI $[.91, .93]$ & .63 & .68 & EOE: .85, 95\% CI[.83, 87] & EOE: . $85,95 \%$ CI[ $[83, .87]$ \\
\hline & & & & & LST: .75, 95\% CI[.70, .78] & LST: . $.80,95 \%$ CI $[.77,82]$ \\
\hline AES & $.89,95 \% \mathrm{CI}[.88, .91]$ & $.89,95 \%$ CI[.87, .91] & .04 & .17 & $.67,95 \%$ CI[.61, .72] & $.67,95 \%$ CI $[.62, .72]$ \\
\hline
\end{tabular}

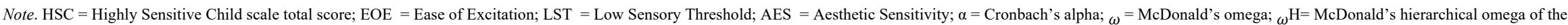




\section{Table 6}

Descriptive Statistics and Intercorrelations of the HSC-21 Scale the Original HSC-12 Scale in Sample 1

\begin{tabular}{|c|c|c|c|c|c|c|c|}
\hline \multicolumn{8}{|c|}{ HSC-21 (21 items) } \\
\hline & $M(S D)$ & Skewness & Median & HSC & EOE-LST & AES & Original counterpart (HSC12) \\
\hline HSC & $3.97(0.82)$ & -.05 & 3.95 & - & $.89 * * *$ & $.67 * * *$ & $.76^{* * *}$ \\
\hline EOE-LST & $3.64(1.00)$ & .00 & 3.69 & & - & $26^{* * *}$ & $.73 * * *(\mathrm{EOE}) / .64 * * *(\mathrm{LST})$ \\
\hline AES & $4.52(1.03)$ & -.16 & 4.5 & & & - & $.49 * * *$ \\
\hline \multicolumn{8}{|c|}{ Original HSC scale (12 items) } \\
\hline & $M(S D)$ & Skewness & Median & HSC & EOE & LST & AES \\
\hline $\mathrm{HSC}$ & $4.54(0.86)$ & -.36 & 4.58 & - & $.83 * * *$ & $.72 * * *$ & $.56^{* * *}$ \\
\hline EOE & $4.13(1.17)$ & 1.17 & 4.20 & & - & $.41 * * *$ & $.15 * * *$ \\
\hline LST & $3.86(1.49)$ & 1.49 & 4.00 & & & - & $.15^{* * *}$ \\
\hline AES & $5.55(0.97)$ & .97 & 5.75 & & & & - \\
\hline
\end{tabular}

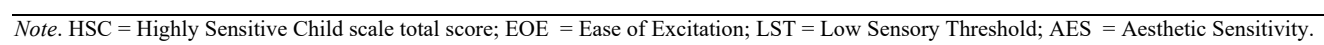




\section{Table 7}

Descriptive Statistics and Intercorrelations of the HSC-21 and the Original HSC-12 scale for Child and Mother Reports in Sample 2 HSC-21 (21 items)

\begin{tabular}{|c|c|c|c|c|c|c|c|c|c|c|}
\hline & \multirow[b]{2}{*}{$M(S D)$} & \multirow[b]{2}{*}{ Skewness } & \multirow[b]{2}{*}{ Median } & \multirow[b]{2}{*}{$\begin{array}{l}\text { HSC } \\
\text { —child }\end{array}$} & \multirow[b]{2}{*}{ EOE-LST child } & \multirow[b]{2}{*}{$\begin{array}{l}\text { AES- } \\
\text { Child }\end{array}$} & \multirow[b]{2}{*}{$\begin{array}{l}\mathrm{HSC}- \\
\text { mother }\end{array}$} & \multirow[b]{2}{*}{$\begin{array}{c}\text { EOE-LST- } \\
\text { mother }\end{array}$} & \multirow[b]{2}{*}{$\begin{array}{l}\text { AES- } \\
\text { mother }\end{array}$} & \multirow[b]{2}{*}{$\begin{array}{c}\text { Original counterpart } \\
\text { (HSC-12) }\end{array}$} \\
\hline & & & & & & & & & & \\
\hline HSC—child & $\begin{array}{l}3.94 \\
(0.87)\end{array}$ & 0.06 & 3.90 & - & $.92 * * *$ & $.69 * * *$ & $.29 * *$ & $.33^{* *}$ & .11 & $.83^{* * *}$ \\
\hline EOE-LST—child & $\begin{array}{l}3.50 \\
(1.08)\end{array}$ & 0.26 & 3.39 & & - & $.35 * * *$ & $.26^{* *}$ & $.32 * *$ & .06 & $\begin{array}{c}.77 * * *(\mathrm{EOE}) / \\
.73^{* * *}(\mathrm{LST})\end{array}$ \\
\hline AES — child & $\begin{array}{l}4.65 \\
(0.97)\end{array}$ & -0.23 & 4.62 & & & - & $.23^{*}$ & $.22 *$ & .15 & $.57 * * *$ \\
\hline $\mathrm{HSC}$ - mother & $\begin{array}{r}4.48 \\
(1.06)\end{array}$ & -0.22 & 4.52 & & & & - & $.94 * * *$ & $.77 * * *$ & $.91 * * *$ \\
\hline EOE-LST- & 4.05 & -0.09 & 4.08 & & & & & - & $.50 * * *$ & $.82 * * *(\mathrm{EOE}) /$ \\
\hline mother & $(1.26)$ & & & & & & & & & $.81 * * *(\mathrm{LST})$ \\
\hline AES - mother & $\begin{array}{l}5.17 \\
(1.13)\end{array}$ & -0.63 & 5.25 & & & & & & - & $.74 * * *$ \\
\hline
\end{tabular}




\begin{tabular}{|c|c|c|c|c|c|c|c|c|c|c|c|}
\hline & \multicolumn{11}{|c|}{ Original HSC scale (12 items) } \\
\hline & $M(S D)$ & Skewness & Median & $\begin{array}{l}\mathrm{HSC}- \\
\text { child }\end{array}$ & $\begin{array}{c}\mathrm{EOE}- \\
\text { child }\end{array}$ & $\begin{array}{l}\text { LST- } \\
\text { child }\end{array}$ & $\begin{array}{l}\mathrm{AES}- \\
\text { child }\end{array}$ & $\begin{array}{l}\text { HSC- } \\
\text { mother }\end{array}$ & EOE-mother & $\begin{array}{l}\text { LST- } \\
\text { mother }\end{array}$ & AES-mother \\
\hline HSC—child & $\begin{array}{l}4.41 \\
(0.79)\end{array}$ & -0.11 & 4.42 & - & $.89 * * *$ & $.71 * * *$ & $.51 * * *$ & $.37 * * *$ & $.33 * * *$ & $.30 * *$ & .18 \\
\hline EOE—child & $\begin{array}{l}4.04 \\
(1.12)\end{array}$ & 0.04 & 4.00 & & . & $.47 * * *$ & $.21 * *$ & $.28^{* *}$ & $.30 * *$ & .18 & .11 \\
\hline LST_child & $\begin{array}{l}3.55 \\
(1.34)\end{array}$ & 0.47 & 3.33 & & & - & .02 & $.31 * *$ & $.22 *$ & $.43 * * *$ & .05 \\
\hline AES — child & $\begin{array}{l}3.55 \\
(0.88)\end{array}$ & -0.78 & 5.50 & & & & - & $.20^{*}$ & .16 & .04 & $.28 * *$ \\
\hline HSC - mother & $\begin{array}{l}4.85 \\
(1.00)\end{array}$ & -0.27 & 4.92 & & & & & - & $.88 * * *$ & $.80 * * *$ & $.64 * * *$ \\
\hline EOE - mother & $\begin{array}{c}4.55 \\
(1.36)\end{array}$ & -0.35 & 4.60 & & & & & & - & $.56^{* * *}$ & $.35 * * *$ \\
\hline LST-mother & $\begin{array}{l}4.52 \\
(1.49)\end{array}$ & -0.33 & 4.67 & & & & & & & - & $.34 * * *$ \\
\hline AES - mother & $\begin{array}{r}5.48 \\
(0.96)\end{array}$ & -0.65 & 5.50 & & & & & & & & - \\
\hline
\end{tabular}




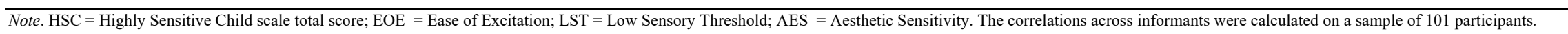

The values in bold are the correlations between the same (sub)scales across informants.

${ }^{*} p<.05 ; * * p<.01 ; * * * p<.001$ 
Table 8

Bivariate Zero-Order and Partial Correlations Between the Highly Sensitive Child Scale (21 Items) and Personality and Temperament in Sample 1 and 2

\begin{tabular}{|c|c|c|c|c|c|}
\hline & \multicolumn{3}{|c|}{ Sample 1} & & \\
\hline & \multirow{2}{*}{$\begin{array}{c}\text { HSC } \\
\text { Zero-order }\end{array}$} & \multicolumn{2}{|c|}{ EOE-LST } & \multicolumn{2}{|c|}{ AES } \\
\hline & & Zero-order & Partial & Zero-order & Partial \\
\hline \multicolumn{6}{|l|}{ Personality } \\
\hline Neuroticism & $.12 *$ & $.10^{*}$ & .08 & .09 & .07 \\
\hline Extraversion & -.02 & -.02 & -.02 & -.01 & -.00 \\
\hline Openness & .02 & -.04 & -.08 & $.11^{*}$ & $.12 *$ \\
\hline Agreeableness & -.01 & .04 & .06 & -.09 & $-.10^{*}$ \\
\hline Conscientiousness & -.08 & $-.10^{*}$ & $-.10^{*}$ & -.01 & .02 \\
\hline \multicolumn{6}{|l|}{ Temperament } \\
\hline Negative Affect & $.23 * * *$ & $.21 * * *$ & $.18^{* * *}$ & $.14 * *$ & .09 \\
\hline Effortful Control & $-.15^{* *}$ & $-.14 * *$ & $-.12 * *$ & -.09 & -.06 \\
\hline Extraversion & -.09 & $-.11^{*}$ & $-.11 *$ & -.01 & .02 \\
\hline Orienting Sensitivity & $.14^{* *}$ & $.11^{*}$ & .09 & $.11^{*}$ & .08 \\
\hline \multicolumn{6}{|c|}{ Sample 2 : Mother report } \\
\hline & $\mathrm{HSC}$ & \multicolumn{2}{|c|}{ EOE-LST } & \multicolumn{2}{|c|}{ AES } \\
\hline & Zero-order & Zero-order & Partial & Zero-order & Partial \\
\hline \multicolumn{6}{|l|}{ Personality } \\
\hline Neuroticism & $.47 * * *$ & $.50 * * *$ & $.46^{* * *}$ & $.24 * * *$ & -.03 \\
\hline Extraversion & $-.22 * * *$ & $-.30^{* * *}$ & $-.36^{* * *}$ & .01 & $.19 * *$ \\
\hline Openness & .07 & -.04 & $-.19 * *$ & $.23 * * *$ & $.29 * * *$ \\
\hline Agreeableness & $-.26 * * *$ & $-.28 * * *$ & $-.27 * * *$ & -.11 & .05 \\
\hline Conscientiousness & -.06 & -.11 & $-.15 * *$ & .04 & .11 \\
\hline
\end{tabular}


HIGHLY SENSITIVE CHILD SCALE 21-ITEM VERSION

Sample 2 : Mother report

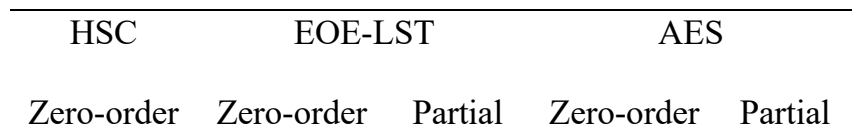

\section{Temperament}

$\begin{array}{llllll}\text { Negative Affect } & .75 * * * & .79 * * * & .73 * * * & .43 * * * & .08 \\ \text { Effortful Control } & -.40 * * * & -.43 * * * & -.41 * * * & -.20 * * * & -.03 \\ \text { Extraversion } & -.44 * * * & -.54 * * * & -.56 * * * & -.10 * & .26 * * * \\ \text { Orienting Sensitivity } & .64 * * * & .50 * * * & .25 * * * & .66^{* * *} & .61 * * *\end{array}$

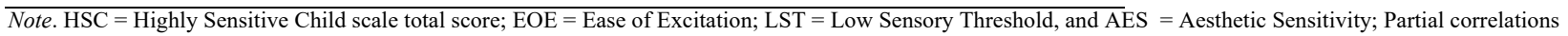

control for the contribution of the other group factors, zero-order correlations do not.. In Sample 1 environmental sensitivity was reported by children, personality and temperament were reported by mothers; $n=417$. In Sample 2 all measures were reported by mothers; $n=542$ for the temperament measures; and $n=316$ for the personality measures because personality was administered two weeks later (drop-out $=42 \%$ ).

${ }^{*} p<.05 ; * * p<.01 ; * * * p<.001$ 


\section{Table 9}

Hierarchical Regression Analysis of HSC-24 (total scale) as a Moderator in the Relation Between Parenting and Internalizing and Externalizing problem behaviors (Sample 1 and 2)

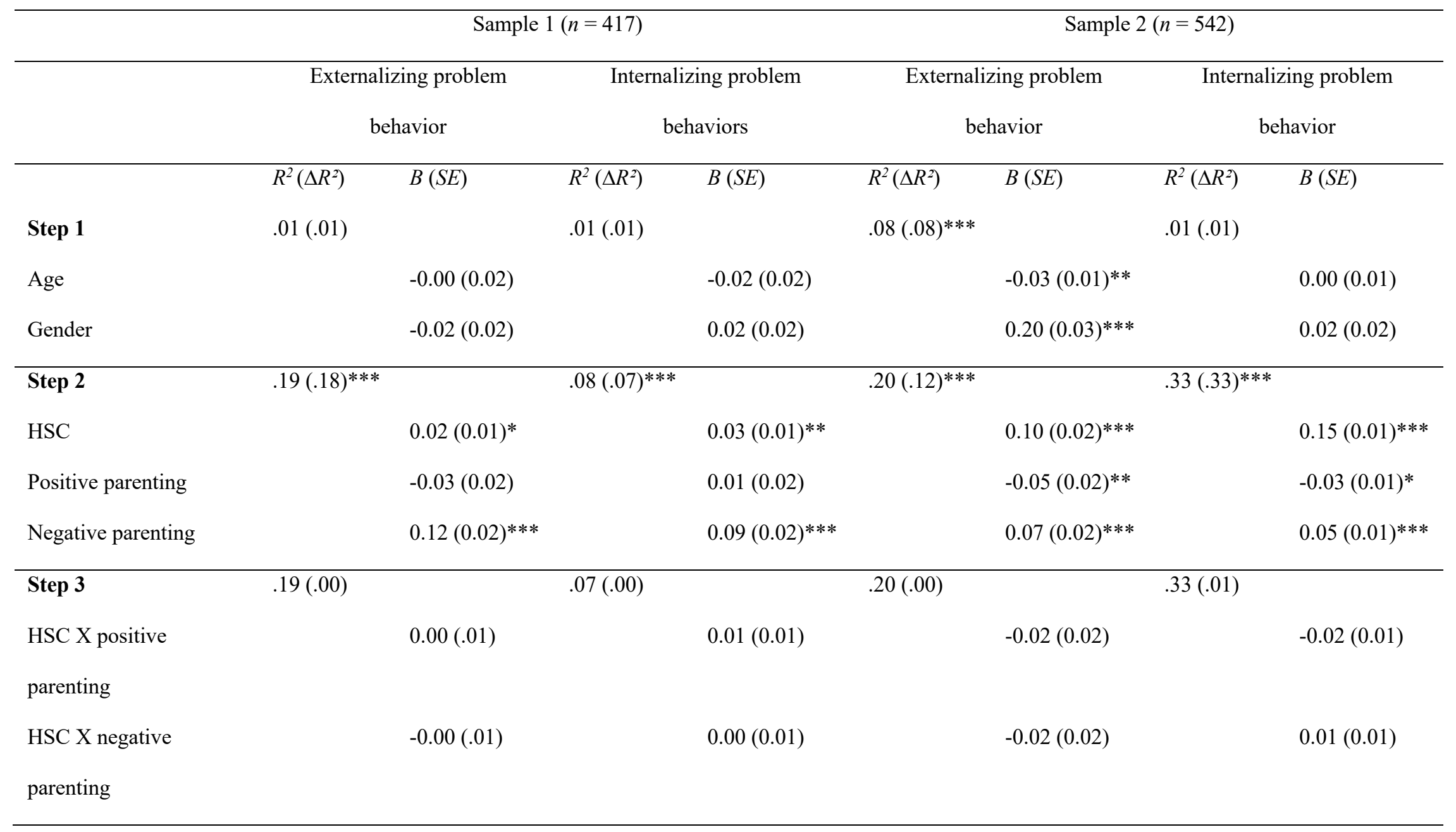

Note. HSC = Highly Sensitive Child scale total score. HSC in Sample 1 is child report; HSC in Sample 2 is mother report. Parenting and outcome variables are reported by mothers in both studies. Because of the large amount of information, only the unstandardized coefficients from Step 3 were reported in the table. In Sample 1 missing data were imputed with a multiple imputation technique. Coefficients are based on pooled results, model summary statistics are based on the original data. Results across imputed data sets were similar: Externalizing Problem Behavior: $R^{2}\left(\Delta R^{2}\right)=.01\left(.01\right.$; Step 1), $.18(.17 \text {; Step } 2)^{* * *}, .18(.00$; Step 3$)$ for Imputed data set 1; .01 (.01; Step 1), $.18(.17 \text {; Step } 2)^{* * *}, .18(.00$; Step 3) for Imputed data set 2; .01 (.01; Step 


\section{Table 10}

Hierarchical Regression Analysis of HSC-24 (subscales) as a Moderator in the Relation Between Parenting and Internalizing and Externalizing problem behaviors (Sample 1 and 2)

\begin{tabular}{|c|c|c|c|c|c|c|c|c|}
\hline & \multicolumn{4}{|c|}{ Sample $1(n=417)$} & \multicolumn{4}{|c|}{ Sample $2(n=542)$} \\
\hline & Externalizir & roblem behavior & Internalizin & roblem behavior & Externalizing & roblem behavior & Internalizing $\mathrm{p}$ & roblem behavior \\
\hline & $R^{2}\left(\Delta R^{2}\right)$ & $B(S E)$ & $R^{2}\left(\Delta R^{2}\right)$ & $B(S E)$ & $R^{2}\left(\Delta R^{2}\right)$ & $B(S E)$ & $R^{2}\left(\Delta R^{2}\right)$ & $B(S E)$ \\
\hline Step 1 & $.01(.01)$ & & $.01(.01)$ & & $.08(.08)$ & & $.00(.00)$ & \\
\hline Age & & $-0.00(0.02)$ & & $-0.02(.02)$ & & $-0.03(.01)^{* *}$ & & $0.00(0.01)$ \\
\hline Gender & & $-0.02(0.02)$ & & $0.02(0.02)$ & & $0.20(0.03)^{* * *}$ & & $0.02(0 . .02)$ \\
\hline Step 2 & $.19(.18)^{* * *}$ & & $.09(.08)^{* * *}$ & & $.20(.12)^{* * *}$ & & $.35(.35)^{* * *}$ & \\
\hline EOE-LST & & $0.01(0.01)$ & & $0.02(0.01)$ & & $0.09(0.02)^{* * *}$ & & $\begin{array}{c}0.15 \\
(0.01)^{* * *}\end{array}$ \\
\hline AES & & $0.01(0.01)$ & & $0.01(0.01)$ & & $0.03(0.02)$ & & $0.01(0.01)$ \\
\hline Positive parenting & & $-0.03(0.02)$ & & $0.01(0.02)$ & & $-0.05(0.02)^{*}$ & & $-0.02(0.01)$ \\
\hline Negative parenting & & $0.12(0.02)^{* * *}$ & & $0.09(0.02)^{* * *}$ & & $0.07(0.02)^{* * *}$ & & $\begin{array}{c}0.04 \\
(0.01)^{* * *}\end{array}$ \\
\hline
\end{tabular}




\begin{tabular}{lcccc}
\hline & \multicolumn{2}{c}{ Sample 1 $(n=417)$} & & Sample 2 $(n=542)$ \\
\hline & Externalizing problem behavior & Internalizing problem behavior & Externalizing problem behavior & Internalizing problem behavior \\
\hline Step 3 & $.19(.00)$ & $.09(.00)$ & $.20(.00)$ & $-36(.01)$ \\
EOE-LST X positive & $-0.00(0.01)$ & $0.00(0.01)$ & $-0.02(0.02)$ & $-0.02(0.02)$ \\
parenting & & & $-0.00(0.01)$ & $-0.01(0.01)$ \\
EOE-LST X negative & $-0.00(0.01)$ & & $0.00(0.02)$ \\
parenting & & $0.01(0.01)$ & $-0.00(0.02)$ \\
AES X positive parenting & $0.01(0.01)$ & $0.00(0.01)$ & $0.01(0.01)$ \\
AES X negative parenting & $0.00(0.01)$ & & $0.01(0.01)$ \\
\hline
\end{tabular}

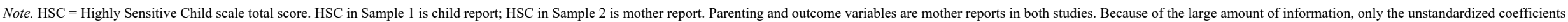

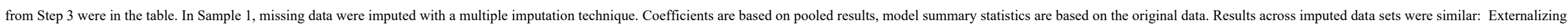

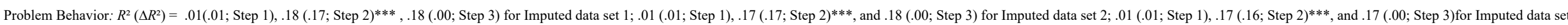

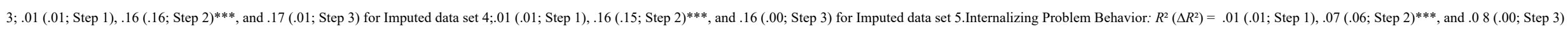

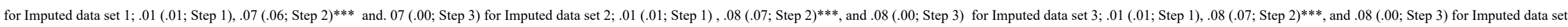
4;.01 (.01; Step 1), .08 (.07; Step 2)***, and .08 (.00; Step 3) for Imputed data set 5.

${ }^{*} p<.05 ; * * p<.01 ; * * * p<.001$ 


\section{Supplementary Material 1}

\section{Extended version of the HSC scale (38 items)}

For each description below, please indicate how strongly it applies to you by circling a number between 1 and 7 .

$\begin{array}{rrrrrrr}1 & 2 & 3 & 4 & 5 & 6 & 7 \\ \text { Not at all } & & & \text { Moderately } & & \text { Very much }\end{array}$

1) I notice when small things have changed in my environment. (HSC1)

$$
\begin{array}{llllllll}
1 & 2 & 3 & 4 & 5 & 6 & 7
\end{array}
$$

2) Loud noises make me feel uncomfortable. (HSC2)

$\begin{array}{llllllll}1 & 2 & 3 & 4 & 5 & 6 & 7\end{array}$

3) I love nice smells.

$\begin{array}{llllllll}1 & 2 & 3 & 4 & 5 & 6 & 7\end{array}$

4) I get nervous when I have to do a lot in a little time. (HSC3)

$\begin{array}{llllllll}1 & 2 & 3 & 4 & 5 & 6 & 7\end{array}$

5) Some music can make me really happy.

$$
\begin{array}{llllllll}
1 & 2 & 3 & 4 & 5 & 6 & 7
\end{array}
$$

6) I am annoyed when people try to get me to do too many things at once.

$$
\begin{array}{lllllll}
1 & 2 & 3 & 4 & 5 & 6 & 7
\end{array}
$$

7) I don't like watching TV programs with a lot of violence in them.

$$
\begin{array}{lllllll}
1 & 2 & 3 & 4 & 5 & 6 & 7
\end{array}
$$

8) I find it unpleasant when a lot is going on at once. (HSC4)

$\begin{array}{lllllll}1 & 2 & 3 & 4 & 5 & 6 & 7\end{array}$


9) I don't like it when things change in my life.

$\begin{array}{llllllll}1 & 2 & 3 & 4 & 5 & 6 & 7\end{array}$

10) I love nice tastes.

$\begin{array}{llllllll}1 & 2 & 3 & 4 & 5 & 6 & 7\end{array}$

11) I don't like loud noises. (HSC5)

$\begin{array}{llllllll}1 & 2 & 3 & 4 & 5 & 6 & 7\end{array}$

12) When someone observes me, I get nervous. This makes me perform worse than normal. (HSC6)

$\begin{array}{llllllll}1 & 2 & 3 & 4 & 5 & 6 & 7\end{array}$

13) Music often moves me deeply.

$\begin{array}{llllllll}1 & 2 & 3 & 4 & 5 & 6 & 7\end{array}$

14) I quickly notice how something smells. (HSC7)

$\begin{array}{llllllll}1 & 2 & 3 & 4 & 5 & 6 & 7\end{array}$

15) How food tastes matters me very much. (HSC8)

$\begin{array}{llllllll}1 & 2 & 3 & 4 & 5 & 6 & 7\end{array}$

16) I usually think a long time about something before I make a decision.

17) In crowded places I quickly get overwhelmed. (HSC9)

$\begin{array}{lllllll}1 & 2 & 3 & 4 & 5 & 6 & 7\end{array}$

18) I notice small details in my surroundings. (HSC10)

$\begin{array}{llllllll}1 & 2 & 3 & 4 & 5 & 6 & 7\end{array}$


19) I quickly feel pain. (HSC11)

$\begin{array}{lllllll}1 & 2 & 3 & 4 & 5 & 6 & 7\end{array}$

20) I am good at distinguishing different tastes. (HSC12)

$\begin{array}{lllllll}1 & 2 & 3 & 4 & 5 & 6 & 7\end{array}$

21) I easily notice how others are feeling.

$\begin{array}{lllllll}1 & 2 & 3 & 4 & 5 & 6 & 7\end{array}$

22) I find coarse or itchy fabrics unpleasant.

$\begin{array}{lllllll}1 & 2 & 3 & 4 & 5 & 6 & 7\end{array}$

23) When picking out clothes, I take into account how they feel.

$\begin{array}{lllllll}1 & 2 & 3 & 4 & 5 & 6 & 7\end{array}$

24) I startle when being touched. (HSC13)

$\begin{array}{lllllll}1 & 2 & 3 & 4 & 5 & 6 & 7\end{array}$

25) I am sensitive to bright light. (HSC14)

$\begin{array}{lllllll}1 & 2 & 3 & 4 & 5 & 6 & 7\end{array}$

26) I immediately notice when someone has new clothes or a new haircut. (HSC15)

$\begin{array}{lllllll}1 & 2 & 3 & 4 & 5 & 6 & 7\end{array}$

27) I am sensitive to loud noises. (HSC16)

$\begin{array}{lllllll}1 & 2 & 3 & 4 & 5 & 6 & 7\end{array}$

28) I am easily overwhelmed by strong smells.

$\begin{array}{llllllll}1 & 2 & 3 & 4 & 5 & 6 & 7\end{array}$


29) I have an eye for details in my surroundings. (HSC17)

$\begin{array}{lllllll}1 & 2 & 3 & 4 & 5 & 6 & 7\end{array}$

30) Unpleasant tastes repulse me.

$\begin{array}{lllllll}1 & 2 & 3 & 4 & 5 & 6 & 7\end{array}$

31) I get startled by sudden noises. (HSC18)

$\begin{array}{lllllll}1 & 2 & 3 & 4 & 5 & 6 & 7\end{array}$

32) I have a delicate sense of smell. (HSC19)

$\begin{array}{lllllll}1 & 2 & 3 & 4 & 5 & 6 & 7\end{array}$

33) I find background noises very bothersome.

$\begin{array}{lllllll}1 & 2 & 3 & 4 & 5 & 6 & 7\end{array}$

34) I use as much information around me as possible before I get started on something.
$\begin{array}{lllllll}1 & 2 & 3 & 4 & 5 & 6 & 7\end{array}$

35) I am sensitive to being touched. (HSC20)

$\begin{array}{lllllll}1 & 2 & 3 & 4 & 5 & 6 & 7\end{array}$

36) I easily think that something smells or tastes strong.
$\begin{array}{lllllll}1 & 2 & 3 & 4 & 5 & 6 & 7\end{array}$

37) I get upset when other children touch me. (HSC21)

$\begin{array}{lllllll}1 & 2 & 3 & 4 & 5 & 6 & 7\end{array}$

38) I am picky about what I eat.

$\begin{array}{lllllll}1 & 2 & 3 & 4 & 5 & 6 & 7\end{array}$

Note. Items in bold are the original HSC-12 items. Items in italic are the retained HSC-21 items. The Dutch version can be obtained by the first author. 


\section{Supplementary Material 2}

\section{Figure S1}

Results of the Hull Method in Sample 1 (Calibration Part).

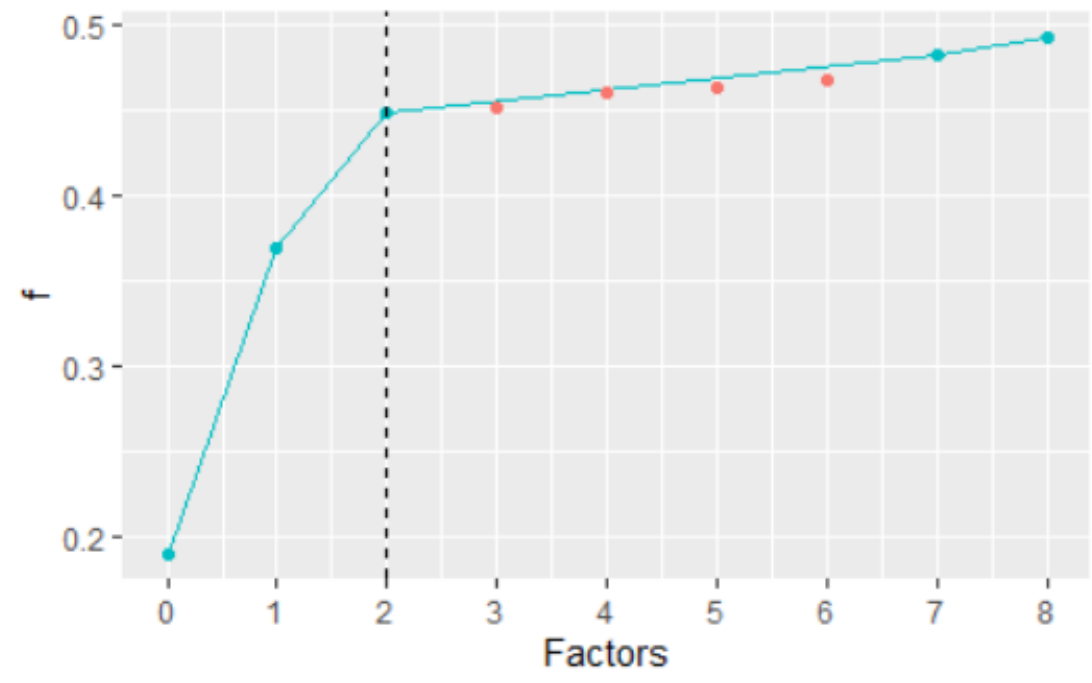




\section{Supplementary Material 3}

Table S1

Standardized Factor Loadings of the Three Factor Correlated Traits Model

\begin{tabular}{|c|c|c|c|}
\hline & EOE & LST & AES \\
\hline Item & $\lambda_{1}$ & $\lambda_{2}$ & $\lambda_{3}$ \\
\hline 4. I get nervous when I have to do a lot in little time & 0.09 & $0.45 * *$ & 0.15 \\
\hline 6. I am annoyed when people try to get me to do too many things at once & 0.18 & 0.28 & 0.19 \\
\hline 8. I find it unpleasant to have a lot going on at once & 0.06 & $0.45 * * *$ & 0.13 \\
\hline 9. I don't like it when things change in my life & 0.00 & $0.30 * * *$ & 0.08 \\
\hline $\begin{array}{l}\text { 12. When someone observes me, I get nervous. This makes me perform } \\
\text { worse than normal }\end{array}$ & 0.08 & $0.45 * * *$ & -0.07 \\
\hline 17. In crowded places I quickly get overwhelmed & 0.01 & $0.45 * * *$ & 0.08 \\
\hline 2. Loud noises make me feel uncomfortable & -0.43 & $0.76^{* *}$ & 0.07 \\
\hline 11. I don't like loud noises & -0.26 & $0.61 *$ & -0.05 \\
\hline 19. I quickly feel pain & 0.22 & 0.35 & 0.01 \\
\hline 22. I find coarse or itchy fabrics unpleasant. & 0.13 & 0.08 & 0.28 \\
\hline 23 When picking out clothes, I take into account how they feel & 0.15 & 0.0 & 0.17 \\
\hline 24. I startle when being touched & 0.37 & 0.43 & -0.09 \\
\hline 25. I am sensitive to bright light & -0.06 & $0.55 * * *$ & 0.09 \\
\hline 27. I am sensitive to loud noises & -0.13 & $0.73 * * *$ & 0.00 \\
\hline 28. I am easily overwhelmed by strong smells & 0.10 & 0.22 & $0.44 * * *$ \\
\hline
\end{tabular}




\begin{tabular}{|c|c|c|c|}
\hline & EOE & LST & AES \\
\hline Item & $\lambda_{1}$ & $\lambda_{2}$ & $\lambda_{3}$ \\
\hline 30. Unpleasant tastes repulse me & 0.19 & 0.20 & 0.20 \\
\hline 31. I get startled by sudden noises & 0.13 & $0.58 * * *$ & -0.07 \\
\hline 33. I find background noises very bothersome & 0.14 & $0.38 *$ & -0.09 \\
\hline 35. I am sensitive to being touched & $0.36 * * *$ & 0.48 & 0.00 \\
\hline 36. I easily think that something smells or tastes strong & 0.05 & 0.09 & $0.53 * * *$ \\
\hline 37. I get upset when other children touch me & 0.28 & 0.39 & -0.08 \\
\hline 38. I am picky about what I eat & $0.37 *$ & 0.13 & 0.13 \\
\hline 1. I notice when small things have changed in my environment & 0.03 & 0.11 & $0.41 * * *$ \\
\hline 13. Music often moves me deeply & 0.18 & 0.25 & 0.05 \\
\hline 14. I quickly notice how something smells & -0.18 & $0-0.12$ & $0.62 * * *$ \\
\hline 15. How food tastes matters me very much & 0.08 & -0.01 & $0.42 * * *$ \\
\hline 16. I usually think a long time about something before I make a decision & 0.04 & 0.13 & 0.10 \\
\hline 18. I notice small details in my surroundings & -0.09 & 0.15 & $0.50 * * *$ \\
\hline 20. I am good at distinguishing different tastes & -0.11 & -0.11 & $0.59 * * *$ \\
\hline 21. I easily notice how others are feeling. & 0.03 & $0.16^{*}$ & $0.36^{* * *}$ \\
\hline 26. I immediately notice when someone has new clothes or a new haircut. & 0.11 & -0.03 & $0.42 * * *$ \\
\hline 29. I have an eye for details in my surroundings. & 0.07 & 0.07 & $0.62 * * *$ \\
\hline 32. I have a delicate sense of smell & -0.03 & -0.10 & $0.58 * * *$ \\
\hline
\end{tabular}


34. I use as much information around me as possible before I get started 0.16 


\section{Supplementary Material 4}

\section{Table S2}

Added Correlated Error Terms Between Highly Correlated Items Tapping Similar Content in the Final Factor Solution of the HSC-21 Scale

\begin{tabular}{|c|c|}
\hline Item & Item \\
\hline I have a delicate sense of smell (HSC19) & I quickly notice how something smells (HSC7) \\
\hline I am sensitive to being touched (HSC20) & I startle when being touched (HSC13) \\
\hline $\begin{array}{l}\text { I get upset when other children touch me } \\
\text { (HSC21) }\end{array}$ & I startle when being touched (HSC13) \\
\hline I don't like loud noises (HSC5) & $\begin{array}{l}\text { Loud noises make me feel uncomfortable } \\
\text { (HSC2) }\end{array}$ \\
\hline $\begin{array}{l}\text { I get upset when other children touch me } \\
\text { (HSC21) }\end{array}$ & I am sensitive to being touched (HSC20) \\
\hline $\begin{array}{l}\text { I notice small details in my surroundings } \\
\text { (HSC10) }\end{array}$ & $\begin{array}{l}\text { I notice when small things have changed in my } \\
\text { environment (HSC1) }\end{array}$ \\
\hline $\begin{array}{l}\text { I get nervous when I have to do a lot in } \\
\text { little time (HSC3) }\end{array}$ & $\begin{array}{l}\text { I find it unpleasant to have a lot going on at } \\
\text { once (HSC4) }\end{array}$ \\
\hline I don't like loud noises (HSC5) & I am sensitive to loud noises (HSC16) \\
\hline $\begin{array}{l}\text { Loud noises make me feel uncomfortable } \\
\text { (HSC2) }\end{array}$ & I am sensitive to loud noises (HSC16) \\
\hline $\begin{array}{l}\text { I notice small details in my surroundings } \\
\text { (HSC10) }\end{array}$ & $\begin{array}{l}\text { I have an eye for details in my surroundings } \\
\text { (HSC17) }\end{array}$ \\
\hline
\end{tabular}




\section{Supplementary Material 5}

\section{Table S3}

The Agreement Between Child and Mother Reports at Item Level of the HSC-21 Scale in Sample 2

rchild_mother

\section{EOE-LST}

Loud noises make me feel uncomfortable (HSC2)

I get nervous when I have to do a lot in little time (HSC3)

I find it unpleasant to have a lot going on at once (HSC4)

I don't like loud noises (HSC5)

When someone observes me, I get nervous. This makes me perform

worse than normal (HSC6)

In crowded places I quickly get overwhelmed (HSC9)

I quickly feel pain (HSC11)

I startle when being touched (HSC13)

I am sensitive to bright light (HSC14)

I am sensitive to loud noises (HSC16)

I get startled by sudden noises (HSC18)

I am sensitive to being touched (HSC20)

I get upset when other children touch me (HSC21)

\section{AES}

I notice when small things have changed in my environment (HSC1)

I quickly notice how something smells (HSC7)

How food tastes matters me very much (HSC8)

I notice small details in my surroundings (HSC10) 
$r_{\text {child mother }}$

I am good at distinguishing different tastes (HSC12) $-.02$

I immediately notice when someone has new clothes or a new haircut $.25^{*}$

(HSC15)

I have an eye for details in my surroundings (HSC17)

I have a delicate sense of smell (HSC19)

$-.08$ 